\title{
Estimating the Value and Interest Rate Risk of Interest-Bearing Transactions Deposits
}

\author{
James M. O'Brien* \\ Division of Research and Statistics \\ Board of Governors \\ Federal Reserve System
}

November 2000

\footnotetext{
${ }^{*}$ Correspondence: Division of Research and Statistics, Board of Governors of the Federal Reserve System, Washington, D.C. 20551; tel: (202) 452-2384, e-mail: jmobrien@frb.gov. The conclusions herein are those of the author and do not represent the views of the Federal Reserve Board. Sheryl Hudson and Sriram Rajan provided outstanding research assistance and Sheryl Hudson made a substantial contribution to the empirical work. Appreciation is acknowledged for helpful discussions and support from Jeremy Berkowitz, Bob Avery, June O’Brien, Gary Anderson, Matt Pritsker, and especially Mark Fisher. Mike Arnold, Mike Gibson, Ray Hawkins, and George Pennacchi provided very helpful comments on various drafts of the paper.
} 


\begin{abstract}
A valuation model is developed within an interest rate contingent claims framework to estimate NOW account and MMDA premiums and interest rate risk for a sample of commercial banks. As has been previously done, bank deposit rate and balances dynamics are represented by autoregressive processes but with attention given here to alternative specifications and to the deposit rent processes and dynamics implied by these specifications. Alternative deposit rate specifications studied include asymmetric adjustment to market rate changes. In examining the implied deposit rent processes, special attention is given to the importance of distant rent forecasts and forecast dynamics for the deposit premium and interest rate risk estimates.
\end{abstract}




\section{Introduction}

Financial institutions routinely apply formal models to value instruments in their portfolios for which current market prices are not readily avaliable. Valuation models are also used for determining market risk exposures and hedges. However, the development of valuation models and interest rate risk measures for transactions deposits, along with bank loans, has proceeded more slowly. Uncertainty about their valuation and risk measurement is also apparent in the rule-makings of bank regulators and accounting boards. ${ }^{1}$

Formal valuation models for transactions deposits are being developed by practioners and academics, although there are still relatively few studies in the public domain. The latter include Office of Thrift Supervision (1994), O’Brien, Orphanides, and Small (1994), and Selvaggio (1996), which provide frameworks based on present values of expected future payments associated with retail deposit liabilities. Hutchison and Pennacchi (1996) and Jarrow and van Deventer (1998) specify formal arbitrage-free pricing models within an interest-rate contingent claims framework. Hutchison and Pennacchi (1996) also estimate retail deposit values and interest rate risk for a sample of commercial banks and Janosi, Jarrow, and Zullo (1999) apply the Jarrow and van Deventer model to a single bank.

A valuation model for transactions deposits is also developed here and applied to individual banks' NOW accounts and money market deposit accounts (MMDAs). The deposit liability value is expressed as current deposit balances minus the present value of future deposit rents, i.e., the deposit "premium". Deposit rents are modeled as an interest rate contingent claim and valued using an arbitrage-free pricing method.

Three features of transactions deposit rate-setting are potentially important to the size and behavior of deposit rents: below-market rates are typically paid, even after accounting for non-interest costs net of fees; deposit rates exhibit stickiness; and rate adjustments tend to be asymmetric, displaying rigidity when market rates are increasing and rate spreads are wide but flexibility when market rates are decreasing and rate spreads are narrow. This

\footnotetext{
${ }^{1}$ Difficulty in measuring the interest rate risk of non-maturity deposits was one factor in not adopting formal interest rate risk capital guidelines for banks' non-trading positions (see Federal Reserve (1995)). The Financial Accounting Standards Board also limits fair value footnote disclosures of demandable liabilities to current balances payable on demand.
} 
behavior is evident in Figure 1 and has been studied, for example, by Moore, Porter, and Small (1990), Hannan and Berger (1991), Neumark and Sharpe (1992), and Ausubel (1992).

To capture deposit rate behavior for deposit valuation purposes, standard practice is to use parsimonious autoregressions relating deposit rates to a short-term market rate, e.g. a U.S. Treasury bill rate. Autoregressive specifications, such as partial adjustment, are used to capture deposit rate stickiness, as well as average market-deposit rate spreads. The standard specifications do not model the asymmetry in deposit rate adjustment, which can be difficult to estimate and can make valuation more difficult. Asymmetry, however, may be important to deposit value and interest rate risk estimates (O'Brien, Orphanides, and Small (1994)). Both asymmetric and symmetric adjustment models are tested and implemented here. These formulations are also applied under fixed and variable deposit balances, with the latter modeled as an autoregressive process that depends on an interest opportunity cost and income.

In relying on parsimonious autoregressions, bank deposit market structure factors also are largely ignored. This greatly simplifies the estimation of deposit rents, which is important given theoretical and empirical limitations in explaining retail deposit pricing (discussed below) and a limited post-deregulation data history. However, whether simplified autoregressive dynamics will capture a bank's true deposit rent process is not clear. Previous cross-sectional studies show that market structure factors, such as market concentration and local population characteristics, are important to the size of "price markups" (e.g., Hannan and Berger (1991), Neumark and Sharpe (1992), Sharpe (1997)). The autoregressive models may be suitable for forecasting near-term deposit rents but not distant rents for which the current market structure cannot be assumed and whose persistence may itself depend on the rents being generated. The importance of long horizon rent forecasts in the deposit valuation and interest rate risk estimates is also studied here.

For alternative deposit rate specifications, we find that asymmetric adjustment provides a statistically better fit to the data than does symmetric adjustment. Estimated premiums also are higher under asymmetric rate adjustment than under symmetric adjustment for NOW accounts; but not for MMDAs. Further, asymmetric adjustment produces asymmetry in the interest rate risk estimates between positive and negative market rate shocks. 
The most reasonable estimates of deposit premiums are obtained under fixed balances. Under variable deposits, the interest rate opportunity cost modifies deposit demand and, hence, estimated premiums. However, for NOW accounts, deposit balances autoregressions produced high predicted deposit growth, which greatly increased longer-term rents.

Long term rent forecasts are important to the estimated deposit premiums. Even with fixed deposits and incorporating non-interest costs, 40 percent or more of the NOW and MMDA premiums are typically accounted for by rents beyond a 10 year horizon.

Long horizon rent dynamics also are important to interest rate risk estimates. Interestinsensitive deposit balances and slow adjusting deposit rates are thought to produce long deposit durations. We show that this notion is not correct when market rates exhibit mean-reversion, which is a standard modeling assumption. In this case, starting from an equilibrium, a shock to the market rate produces an initial shock to deposit rents that, over a period of time, is reversed (in expected value and prior to discounting). The subsequent reversal moderates the deposit value's interest rate elasticity or duration. This moderation produced interest rate inelastic deposit values and durations mostly less than one year.

We begin by specifying and estimating deposit rate and balances equations. A valuation model is then developed and implemented. Following this, deposit premiums and interest rate risk estimates are presented and the role of deposit rents analyzed. In the concluding section, the issue of limited market price information on deposit values is discussed.

\section{Estimating Deposit Rate and Balances Adjustments}

\subsection{Equation Specifications}

NOW and MMDA deposit rate equations are specified to explicitly recognize both deposit rate stickiness and asymmetry in adjustment speeds in rising versus declining market rate environments. For this purpose, the asymmetric partial adjustment model of Neumark and Sharpe (1992) and Moore, Porter and Small (1988)is used here. ${ }^{2}$ This reduces to a

\footnotetext{
${ }^{2}$ Other asymmetric adjustment forms have been tested by Ausubel (1992) and Hannan and Berger (1991). There are also functional forms not explicit on asymmetry but more flexible than the standard (symmetric) partial adjustment model or that recognize higher-order or more complex lag dependencies on market rates (for example, Jarrow and van Deventer (1998) and Hawkins and Arnold (2000)). However, the potential for asymmetric adjustment and its effects on valuation is emphasized here.
} 
standard partial adjustment form under symmetric adjustment, where it is similar to the AR(1) process estimated by Hutchison and Pennacchi (1996). ${ }^{3}$ Bank deposit balances are modeled as satisfying a household desired balances equation such as used in money demand equations. The formal equations, with individual bank subscripting suppressed, are

$$
\begin{aligned}
\Delta R_{t} & =\left(\lambda^{+} I_{t}+\lambda^{-}\left(1-I_{t}\right)\right)\left(R_{t}^{e}-R_{t-1}\right)+e_{t} \\
R_{t}^{e} & =b r_{t}-g \\
I_{t} & \equiv I_{\left[R_{t}^{e}-R_{t-1}>0\right]} \\
\log \left[D_{t}\right] & =a_{1}+a_{2}\left(r_{t}-R_{t}\right)+a_{3} \log \left[Y_{t}\right]+a_{4} \log \left[D_{t-1}\right]+v_{t}
\end{aligned}
$$

$\Delta R_{t}$ is the 1-period change in the deposit rate and $r_{t}$ is a market rate. $R_{t}^{e}$ is a conditional equilibrium rate in that the actual deposit rate adjusts to $R_{t}^{e}$. $I_{t}$ is the indicator function (1 if $R_{t}^{e}-R_{t-1}>0$, 0 otherwise). Depositors' desired balances in (2) depend on an opportunity cost, $r_{t}-R_{t}$, a measure of income, $Y_{t}$, and lagged balances. $e_{t}$ and $v_{t}$ represent zero-mean random disturbances. ${ }^{4}$

Several points on these specifications should be noted. First, individual bank deposit rate adjustments are more discrete in size and less regular in frequency than would be indicated by the partial adjustment specification (see Berger and Hannan (1991) and Kahn, Pennacchi, and Sopranzetti (1999)). The partial adjustment model is a practical way to represent deposit rate stickiness such that the model dynamics are estimable and tractable.

Second, there is no attempt to ensure that the deposit rate and deposit demand specifications are jointly consistent with some underlying model of bank profit maximization. Hutchison and Pennacchi (1996) develop a profit maximizing deposit rate adjustment equation from an imperfectly elastic deposit demand curve but their framework leads to symmetric deposit rate adjustment $\left(\lambda^{+}=\lambda^{-}\right)$. There is not a generally acceptable theoretical explanation for asymmetric deposit rate adjustment, nor is there a consensus explanation

\footnotetext{
${ }^{3}$ Hutchison and Pennacchi (1996) assume that the bank continuously and fully responds to market rate changes. However, due to lagged adjustment in deposit balances, their "reduced-form" deposit rate process has the same structure as in a partial adjustment model. See the model in their Table 1.

${ }^{4}$ While $R_{t}^{e}$ also could have a disturbance term, Neumark and Sharpe (1992) estimated parameters for the deposit rate process with and without including an error term in the equilibrium rate component with little effect on results (pp. 673-674 and Table IV).
} 
for deposit rate rigidity. ${ }^{5}$

Third, under symmetric adjustment $\left(\lambda^{+}=\lambda^{-}\right)$, the unconditional and long-run expected rate equals the unconditional expected equilibrium rate, i.e., $E\left[R_{t}\right]=E_{r_{t}}\left[R_{t}^{e}\right]$. However, under asymmetric deposit rate adjustment, the unconditional expected deposit rate and long-run expected rate diverge from the unconditional mean equilibrium rate, i.e.,

$$
E\left[R_{t}\right]=E_{r_{t}}\left[R_{t}^{e}\right]-\left(1-\frac{\lambda^{+}}{\lambda^{-}}\right) E_{r_{t}, R_{t-1}}\left[\max \left\{R_{t}^{e}-R_{t-1}, 0\right\}\right]
$$

Since $\max \{\quad\}$ in (3) is non-negative, when upward adjustment is slower than downward adjustment $\left(\lambda^{+}<\lambda^{-}\right)$, the unconditional expected deposit rate will be less than the expected value of the equilibrium rate by an amount that is inversely related to the volatility of the market rate. This property of asymmetric deposit rate adjustment was not recognized in earlier deposit rate studies.

\subsection{Deposit Rate and Balances Data}

Bank deposit rates and balances are taken from a Federal Reserve survey of commercial bank rates and balances on interest-bearing transactions accounts since the early 1980s (FR

\footnotetext{
${ }^{5}$ The banking literature has provided evidence relating both rigidity and asymmetry to market power factors but a consensus behavioral explanation for these results is lacking. Hannan and Berger (1991) and Ausubel (1992) discuss difficulties in explaining asymmetric behavior in terms of standard models of imperfect competition. Sharpe (1997) provides a model for deposit rents based on consumer search costs where market structure is explicitly modeled and is critical to the size of the rents. Sharpe's model does provide some basis for forecasting market structure factors that will have predictable effects on the level of deposit rents. However, the analysis is static and does not account for deposit rigidity or asymmetry in response to market rate changes. Kahn, Pennacchi, and Sopranzetti (1999) offer an explanation of the temporal and quantitative discreteness in deposit rate adjustments that is based on depositors having limited memory, but do not explain the asymmetry in responses to market rate increases and decreases. Ausubel (1992) offers one of the few choice-theoretic explanations for asymmetric adjustment. He suggests limited information on market investment alternatives and search costs that lead to the type of rigidity and asymmetry in deposit rate setting that are observed. However, the model also predicts a high probability of loosing deposits when deposit rates are low and spreads are narrow. This is contrary to existing evidence, and that presented below, on deposit flows. Dueker (2000) offers further explanations for asymmetric adjustment in the context of loan rates. In a different but related context, Whitesell (1992) and Hutchison (1995) emphasize the importance of savings versus transactions services provided by transactions accounts in modeling transactions deposit pricing.
} 
2042: Monthly Survey of Selected Deposits and Other Accounts). For this study, the sample period is Jan 1986 - Dec 1994 for NOW accounts and Nov. 1983 - Sept 1991 for MMDAs. The starting dates coincide with full de-regulation of NOW and MMDA rates respectively. MMDA rates ceased to be reported in the monthly survey after Sept. 1991 when MMDAs were combined with savings accounts. ${ }^{6}$ The survey data after 1994 is not used because the NOW balances reported in the surveys since then have become highly distorted by banks' use of "sweeps" to avoid reserve requirements. ${ }^{7}$

Banks not in the samples for the whole period or with missing deposit rates or balances were dropped. This left a sample of 160 banks. From this sample, 25 banks were eliminated for which deposit balances were highly erratic. There was no formal attempt to adjust the data for bank acquisitions and sales. As reported below, additional banks also were lost due to estimation difficulties. Table 1 reports the effects of bank deletions on sample means for deposit rates and means and medians for deposit balances.

\subsection{Deposit Rate Model Estimates}

For each bank, deposit rate adjustment and deposit balances demand equations were separately estimated. Potential simultaneous equation bias is considered in the next section.

In estimating each bank's deposit rate adjustment equations, the market rate is the month-end 3-month Treasury bill yield, the equation residual is assumed to be an i.i.d. zero mean process (see footnote 4 ), and the parameters are estimated with nonlinear least squares using the RATS Gauss-Newton algorithm. For NOW and MMDA deposit rate equations, a total of 36 banks exhibited measurable sensitivity to initial starting values. These banks were deleted from the sample with little effect on the mean deposit rate and only a modest effect on average deposit balances (see Table 1).

For the remaining 99 banks in the sample, a summary of the estimated parameters for the

\footnotetext{
${ }^{6}$ Between July 1989 and Sept. 1994, NOW and MMDA rates and balances were reported for different interest rate tiers. For this period, a deposit balance weighted-average of the tiered rates for NOWs and for MMDAs, respectively, was used. Rates in different tiers generally moved up and down in unison.

${ }^{7}$ Since 1994, many banks have moved temporarily inactive NOW (and non-interest demand) balances into MMDAs in order to reduce reserve requirements. Nonetheless, the swept balances are not reported as MMDAs to depositors and the practice has had little apparent effect on NOW rates paid.
} 
NOW deposit rate equation is presented in Table 2. For the asymmetric adjustment model (top panel), the deposit rate adjustment coefficients when deposit rates are increasing $\left(\lambda^{+}\right)$ are very small, mostly statistically close to zero (the mean coefficient is heavily influenced by several outlier estimates). Statistics in the upper right panel show equilibrium deposit rates during 1986-1994 of 5 percent. This is 80 basis points higher than the average and median NOW rates the banks actually paid and about 75 basis points below the average T-bill rate.

The middle panel summarizes the estimated parameters for the NOW deposit rate equations when the adjustment speed is restricted to be symmetric $\left(\lambda^{+}=\lambda^{-}\right)$. The adjustment speeds are fairly small but all are positive and most have t-values greater than 2 . Average equilibrium rates (middle right panel) are substantially below the average rates paid. Thus the symmetric adjustment model attempts to account for relatively large deposit rate declines and small increases in a period of on-average declining market rates with low equilibrium deposit rates and relatively slow adjustment speeds.

The bottom panel presents tests of the symmetric rate adjustment restriction. The left side reports t-values for the difference in the two sample statistics, $\lambda^{+}$and $\lambda^{-}$. Based on standard significance levels, these t-values are high. The right side reports the likelihood ratio test for the difference between the restricted (symmetric) and unrestricted (asymmetric) sum of squared error estimates. Again, for most banks, the chi-square statistics are very high. These results imply a strong rejection of the symmetry restriction. ${ }^{8}$

MMDA equation estimates for the asymmetric adjustment model are summarized in the top panel of Table 3. Deposit rate adjustment speeds when the deposit rate is adjusting upward, while relatively low when compared to downward adjustment speeds, are substantially higher than they are for NOW account rates. The 1983-1991 sample average and median equilibrium MMDA rates (top right panel) is about 7 percent which is 60 basis points above the average MMDA rate actually paid during the period. Equilibrium rates are about 35 basis points below the average T-bill rate. Results under the symmetry restriction (middle panel) show adjustment speeds for MMDA rates typically about twice

\footnotetext{
${ }^{8}$ These tests, of course, are subject to the standard assumption that the equation residuals are i.i.d. normal variates.
} 
that estimated for NOW rate adjustments. As with NOW rates, under symmetric rate adjustment, the equilibrium rates for MMDAs are below the rates that banks actually paid during the sample period. As with NOW rates, the bottom panel shows that the symmetry restriction for MMDA rates is strongly rejected in statistical tests.

Of the 99 banks whose results are reported in Table 2 and 3, for NOW accounts, 25 banks had a negative adjustment coefficient for $R_{t}^{e}-R_{t-1}>0$ and 4 banks for MMDAs. While small absolutely and not significant, a negative coefficient makes the deposit rate non-stationary (it declines without limit). These banks are eliminated from the simulations reported below in Figure 2 and in the subsequent deposit valuations. Elimination had little effect on the sample mean deposit rate and deposit balances (Table 1) and raised the mean and quantile values for the deposit rate coefficients only a small amount (e.g., the NOW median value for $\lambda_{i}^{+}$increased from .0021 to .0037).

To illustrate the estimated deposit rate behavior, a single market rate path is simulated (see below for more detail on market rate simulations). Based on the simulated market rate path, the respective averages of the banks' NOW and MMDA predicted deposit rate paths using the individual bank estimated equations are plotted in Figure 2. The initial values for the market and bank deposit rates are their respective expected values.

For NOW accounts, the deposit rate is quite sluggish for both models. Nonetheless, the asymmetric rate adjustment model shows a smaller upward adjustment when the marketto-deposit rate spread widens and a quicker adjustment downward when the spread gets narrow, a pattern more closely resembling the actual deposit rate process shown in Figure 1. For MMDA rates, the differences between the two models are small and there is considerably more market rate sensitivity than with NOW accounts.

\subsection{Deposit Balances Demand Estimates}

For estimating deposit balances equations, two measures of nominal income were constructed, monthly series interpolated from quarterly national income and from annual income reported for each bank's MSA (county income for banks without an MSA classification). The performance of the two measures in the regression equations was similar for most banks. Results reported here use the national income series. 
Regression results using OLS are reported in Table 4. For NOW accounts, 91 of 99 banks have negative interest rate coefficients and more than half have t-values in excess of 2 . Most NOW deposit equations display positive income elasticities and more than 80 percent have tvalues in excess of 2 . The most important explanatory variable is lagged deposits (minimum and maximum coefficient values across banks are .239 and .975). For MMDA balances, the estimated interest rate elasticities are higher than those for NOW accounts although the tstatistics are a bit lower. 93 out of 99 banks have negative interest rate elasticities. Income is not a significant explanatory variable for MMDA deposit balances demands. As with NOW account balances, lagged deposits is the most important explanatory variable (minimum and maximum coefficient values are .617 and .992).

The interest rate elasticity $a_{2}$ in the deposit balances demand equation is subject to simultaneous equation bias if the deposit rate adjustment error $e_{t}$ is correlated with $v_{t}$. If the bank pays a lower (higher) rate when demand shocks are positive (negative), the coefficient $a_{2}$ would be biased toward zero. As a check for bias, the spreads between the market and deposit rates in the deposit demand equations for each bank were replaced by spreads that used a predicted deposit rate which would be uncorrelated with the demand equation residual, i.e., the simulated deposit rate for the sample period using the estimated deposit rate adjustment equation, actual market (t-bill) rates, and the bank's deposit rate at the start of the period. For both NOW and MMDA balances equations, the estimated interest rate (and other) coefficients and t-values using the simulated interest rate spread were very similar to the OLS estimates reported in Table 3 (not shown).

In Figure 3, averages for NOW and MMDA simulated paths of the individual banks' log deposit demands are plotted. The plots are conditioned on the same market and deposit interest rate paths used in constructing Figure 2 above. Initial deposit balances are the sample period means for each bank and income is assumed to grow at 3 percent annually. The simulated paths for NOW balances reflect an annual growth in excess of 6 percent annually. There is a slightly negative trend in simulated MMDA balances. ${ }^{9}$ The periodic

\footnotetext{
${ }^{9}$ Annual growths for sample average NOW and MMDA balances were 13 and 3 percent, respectively. When a time trend was included in the regressions, the trend coefficients were positive for NOW balances with a mean t-stat of .79 and negative for MMDAs with a mean t-stat of -.28. The only other material change was that the average income coefficients were now both positive but with very low t-values.
} 
fluctuations in balances that appear in the plots, which are larger for MMDAs, reflect the effects of changing market-to-deposit rate spreads on the deposit balances.

\section{Valuation Model and Implementation}

\subsection{Valuation Framework}

The deposit value estimated here is the expected discounted value of future deposit account payments for the type of account being valued (e.g., the bank's NOW accounts) over an indefinite horizon. An indefinite horizon is used since there is no natural limit to the life of a deposit franchise. The deposit account payments include interest paid, pecuniary non-interest costs, the implicit costs of any reserve requirements, and deposit withdrawals. Deposits are treated as default-free. This valuation will be consistent with the value to the bank's current non-deposit claimants assuming that (i) the deposit value is preserved (future deposit rents fully captured) in the event of a deposit franchise sale, and (ii) deposits have no special advantage over market borrowing in financing bank assets other than the rents earned from paying below market rates (see Berlin and Mester (1999)).

A schema of the deposit payments flows is the following

\section{Deposit Account Payments}

\begin{tabular}{cccc}
\hline$t=0$ & $t=1$ & $t=2$ & $\cdots$ \\
\hline$f D_{0}$ & $\left(R_{0}+C_{0}\right) D_{0}-(1-f) \Delta D_{1}$ & $\left(R_{1}+C_{1}\right) D_{1}-(1-f) \Delta D_{2}$ & $\cdots$
\end{tabular}

$R_{t-1}, D_{t-1}$, and $\Delta D_{t}$ are the lagged deposit rate, deposit balances and current change in deposit balances, respectively. $C_{t-1}$ is non-interest costs net of service fees. $f$ is the required reserve ratio and required reserves are proportional to current deposit balances.

To determine the present value of these payment flows, define $\beta_{t} \equiv e^{\int_{0}^{t} r_{\tau} d \tau}$ as the value at $t$ of $\$ 1$ invested at time 0 in a money market account that continuously pays the (instantaneous) risk-free rate. Also, let $y_{t} \equiv \frac{\beta_{t}}{\beta_{t-1}}-1$ be the realized 1-period return to the money market account. The value of the bank's deposit obligations at time 0 is: 


$$
\begin{aligned}
V_{0} & =f D_{0}+\sum_{t=1}^{\infty} E_{0}^{Q}\left[\frac{\left(R_{t-1}+C_{t-1}\right) D_{t-1}-(1-f) \Delta D_{t}}{\beta_{t}}\right] \\
& =D_{0}-\sum_{t=1}^{\infty} E_{0}^{Q}\left[\frac{\left(y_{t}(1-f)-R_{t-1}-C_{t-1}\right) D_{t-1}}{\beta_{t}}\right]-\lim _{T \rightarrow \infty} E_{0}^{Q}\left[\frac{D_{T}(1-f)}{\beta_{T}}\right]
\end{aligned}
$$

The first line in (4) is the deposit liability value in terms of the periodic net deposit payments. The second line is the current balances liability net of the present value of deposit rents and is obtained through algebraic manipulation of the first line. In (4), $\lim _{T \rightarrow \infty} E_{0}^{Q}\left[\frac{D_{T}(1-f)}{\beta_{T}}\right]$ is assumed to vanish so that only rents need be valued. $E^{Q}[]$ denotes the expected value under a risk-neutral measure and $\beta_{t}$ is the compounded return to a risk-free money market investment. As described below, the expected value under the risk-neutral measure impounds a discount for the deposit rents' systematic risk.

\subsection{Model Implementation}

The deposit value in (4) is estimated for each bank's NOW and MMDA liabilities. The market rate, $r_{t}$, is assumed to adjust continuously, while any deposit rate and balances adjustments and deposit payments occur at a monthly frequency, coinciding with the frequency of the historical observations. These adjustments are estimated using the individual banks' estimated deposit rate and balances equations (1) and (2) that were summarized in Tables 2 and 3 .

In addition, non-interest costs, $C_{t}$, are recognized but assumed to be constant per-dollar of deposit balances. These costs are estimated using average net non-interest costs for NOW accounts and MMDAs in annual functional cost reports for aggregate banks by deposit size over the sample period. ${ }^{10}$ Annualized costs per dollar of deposits are .0120, .0131, and .0148 for small, medium and large size NOW accounts, respectively; and .0075, .0083, and .0088 for MMDAs. The costs are applied to a bank's deposit category in accord with the account type and average balances. For NOW accounts, the monthly reserve requirement ratio $(f)$

\footnotetext{
${ }^{10}$ See Federal Reserve Functional Cost Annual Reports for more detail.Changes in the annual costs perdollar of deposits are small and unrelated to deposit rates.
} 
is set equal to each individual bank's average required ratio for the sample estimation period (1986-1994). Over the sample period, individual bank required reserve ratios displayed little temporal variation.

To describe the valuation method, consider the current value of the rent paid at time $t$.

$$
v_{0 t}=E_{0}^{Q}\left[\pi_{t}\left(y_{t}, r_{t-1}, R_{t-1}, C_{t-1}, Y_{t-1}\right) \frac{1}{\beta_{t}}\right]
$$

where $\pi_{t} \equiv\left(y_{t}(1-f)-R_{t-1}-C_{t-1}\right) D_{t-1}$ is the realized deposit rent. The expectation in equation (5) is under a risk-neutral measure, $Q$, for which the expected rate of return on $v_{0 t}$ equals the risk-free rate. Thus, $E_{0}^{Q}$ embeds the risk premium that would be present in the expected return under the actual process. Determining the proper change of measure for deposit rent valuation is simplified by assuming that deposit rents (deposit rates, balances, and the market rate) depend on a single systematic risk factor, the market rate. ${ }^{11}$ However,a model for the market rate process is needed.

Here, the Cox, Ingersoll, Ross (CIR) 1-factor interest rate model is used. The CIR stochastic market rate process, $d r_{\tau}=\kappa\left(\theta-r_{\tau}\right)+\sigma \sqrt{r_{\tau}} d z_{\tau}$, has the form

$$
d \hat{r}_{\tau}=\left(\kappa \theta-(\kappa+\phi) \hat{r}_{\tau}\right)+\sigma \sqrt{\hat{r}_{\tau}} d \hat{z}_{\tau}
$$

under the risk-neutral measure. $\phi$ is a market risk parameter and $d \hat{z}_{\tau}$ is a standard normal process under the change of measure (see Duffie (1996), chp. 10).

Beside the market rate, the only other exogenous variable is income. With the market rate representing a single risk factor, income uncertainty would affect deposit values (through variable deposit balances) if the income changes were correlated with the market rate. Here, we simply posit a deterministic growth in income of 3 percent annually, and ignore possible systematic income risk on deposit valuation. ${ }^{12}$

To obtain the risk neutral valuation for deposit rents, replace the underlying state variables with their risk-adjusted counterparts and determine the expected discounted value

\footnotetext{
${ }^{11}$ This also is the case for Hutchison and Pennacchi (1996) and Jarrow and van Deventer (1998)

${ }^{12}$ Although not attempted here, Pennacchi (1999) suggests a possible procedure for recognizing systematic income (in his study, wage) risk for valuation. He would determine a market security portfolio whose return risk replicated that of income shocks. Using an assumed pricing model (e.g., the CIR model), determine the risk premium in the expected return on the risk-replicating portfolio and use this premium to adjust the drift in income.
} 
of rents expressed as functions of the transformed state variables. ${ }^{13}$ Here, the market rate is the underlying state variable and variables dependent on the market rate (i.e., $y_{t}, r_{t-1}$, $R_{t-1}$, and $\beta_{t}$ ) are re-expressed in terms of the drift-adjusted market rate. The expected value of the discounted rent is equal to its present value, i.e.,

$$
v_{0 t}=E_{0}\left[\pi_{t}\left(\hat{y}_{t}, \hat{r}_{t-1}, \hat{R}_{t-1}, C_{t-1}, Y_{t-1}\right) \frac{1}{\hat{\beta}_{t}}\right]
$$

where "hats" denote transformed variables. Asymmetric deposit rate adjustment makes it necessary to use numerical methods to determine the expected discounted rents.

1000 paths of the drift-adjusted market rate over a 30 year horizon are simulated with the initial rate at its unconditional expectation (under the actual process). ${ }^{14}$ The parameters for the market rate process in $(6)(\kappa \theta, \kappa+\phi$, and $\sigma)$ are taken from estimates by Chen and Scott (1993 Exhibit 1 p. 20) over a 1960-87 estimation period. ${ }^{15}$ Paths for bank-specific deposit rate adjustment error terms are also simulated and income is compounded at 3 percent annually. ${ }^{16}$ At a monthly frequency, paths of discounted deposit rents for each bank are calculated from the drift-adjusted market rate, deposit rate shock, and income paths. The paths are conditioned on an initial deposit rate equal to its unconditional expected rate, initial deposit balances equal to the bank's sample mean deposits, and initial income at the sample mean. The mean of the simulated discounted rents at month $t$ is the estimate of $v_{0 t}$ in equation (7). Subtracting the sum of monthly deposit rent values from initial deposit balances gives the estimated value of the deposit liability.

\footnotetext{
${ }^{13}$ The expected return to the claim on deposit rents when expressed in terms of the transformed state variables is equal to the risk-free rate which is the basis for determining the claim's value subject to an absence of arbitrage. For details, see Duffie (1996, chp. 5.H) and Fisher and Gilles (1996).

${ }^{14} \mathrm{~A}$ finely discretized version of the market rate process was simulated at 10 nodes per month or 3,600 nodes per path (see Duffie (1996) pp. 247-248 for discretization). A small number of negative market rates, due discreteness, were replaced with 0 .

${ }^{15}$ The parameter estimates are $\kappa=.4697, \theta=.06182, \sigma=.08248, \phi=-.04544$.

${ }^{16}$ The valuations depend on the deposit rate adjustment errors in equation (1) only under asymmetric adjustment. Error paths were constructed for each bank by simulating 1000 paths for an iid standard normal deviate and multiplying each path by the individual bank's estimated residual standard error. The average residual standard error based on monthly changes of annualized deposit rates was only about 12 basis points.
} 


\section{Deposit Premiums}

Following convention, deposit premiums per-dollar of initial deposit balances, $\frac{D_{0}-V_{0}}{D_{0}}$, are presented rather than deposit values. NOW account and MMDA premiums are estimated for each of the 74 and 95 banks whose (asymmetric) deposit rate equations could be simulated (see Table 1 and discussion in section 2.2).

First consider deposit premiums when deposit balances are fixed. Summary statistics for NOW and MMDA premiums and their components are presented in Table 5.a. Under asymmetric deposit rate adjustment, the median NOW premium is 21 percent of initial deposit balances, with $10 \%$ and $90 \%$ quantiles of 8 and 37 percent. Non-interest costs (VNIC) and reserve requirements (VRR) reduce the premiums by about 50 percent. Under symmetric deposit rate adjustment, the median premium is about 15 percent. The range of premiums also is smaller than under asymmetric deposit rate adjustment.

MMDA premiums are similar under the asymmetric and symmetric deposit rate adjustment models, even on a bank-by-bank basis, with median premiums of about 12 percent. The quantile values of the premiums are also similar. This similarity for MMDA premiums under the two adjustment models is consistent with the similarity in the MMDA deposit rate simulations reported in Figure 2.

In Table 5.b, median premiums are presented for when deposit balances are variable (with rents earned on any deposit growth). The first row repeats the median premiums under fixed deposit balances. The second row (variable deposits (a)) reports median premiums where deposit balances reflect both projected growth and interest rate sensitivity. The very large NOW premiums reflect a high level of projected growth in NOW balances (median growth exceeded 6 percent per year). The substantial deposit growth, common to most banks, also greatly increased the cross-section dispersion of deposit premiums (not shown). MMDA premiums are lower under variable than under fixed deposits. As described next, the major reason is the effects of deposit balances interest rate sensitivity.

The third row (variable deposits (b)) reports median premiums with the estimated coefficient for the interest rate opportunity cost in the deposit balances equations set to zero. The difference between the premiums in rows 3 and 2 is a measure of the effects of the deposit balances interest rate sensitivity on the deposit premiums. For MMDAs, 
this interest rate sensitivity accounts for most of the decline between premium estimates in going from fixed to variable deposits premiums. A small decline in projected deposit balances accounts for the rest. For NOW accounts, the absolute effects of the deposit balances interest rate sensitivity are larger due to deposit growth (the deposit balances interest rate elasticity is proportional to the level of deposit balances).

The effects of the rent horizon on the estimated deposit premiums can be assessed with the help of Figure 4. In the top panel is plotted the marginal premiums, i.e., expected discounted monthly rents, for the banks with a median NOW premium under each of the four scenarios for deposit rate and balances adjustments. The bottom panel plots the total premiums (the cumulative marginal premiums) for different horizon truncations. With variable deposits (dash and dash-dot lines), the assumption that marginal premiums are zero after 30 years is strongly violated. This result plus the size of the estimated premiums for a 30-year horizon (Table 5.b) makes these estimates not credible.

For fixed deposits, the marginal premiums are small at 30 years (solid and dotted lines). Nonetheless, they are still sizable after 10 years. The total premium under fixed deposits is 12 percent after 10 years versus 21 percent after 30 years under asymmetric adjustment and 9 and 15 percent, respectively, under symmetric adjustment. For NOW accounts, the marginal premiums are important over a long horizon.

In Figure 5, MMDA marginal and total premiums are plotted for the median banks. The marginal premiums become insignificant at much earlier horizons than for NOW accounts. If rents are truncated at a 10 year horizon, the MMDA premiums for the median banks under fixed deposits are about 8 percent versus 12 percent at 30 years. Under variable deposits, premiums at 10 years are about the same as those at 30 years.

The NOW premiums reported here are considerably higher than in Hutchison and Pennacchi. They reported a median NOW premium of 7 percent, and 8 percent median MMDA premium, restricting deposit growth to zero. For their single bank, Janosi, Jarrow, and Zullo (1999) estimated sample-period median NOW premiums of -7 and 26 percent on a mergeradjusted and merger-unadjusted basis, respectively. Both studies employ valuation models with analytic solutions. Berkovec and Liang (1991) estimated premiums for deposit categories for failed banks (1987-1990) by applying hedonic (cross-section) regression methods 
to the "core deposit premiums" paid by the FDIC. Their regression estimates implied average NOW and MMDA premiums of 5 and 4 percent, respectively. Berkovec, Mingo, and Zhang (1997), however, reported core deposit premiums in private sales of non-failed banks much higher than those paid for failed banks on similarly structured transactions. Thus, how applicable the Berkovec and Liang results are to on-going banks is not clear.

\section{Interest Rate Risk}

\subsection{Interest Rate Elasticity and Deposit Rent Dynamics}

Two measures of deposit value interest rate risk are use here: the deposit value's interest rate elasticity and duration. The former is the percentage change in the deposit value due to a given market rate shock. The latter is defined as the maturity of a zero-coupon bond with the same interest rate elasticity as the deposit value (see Cox, Ingersoll, and Ross (1979)). Market and deposit rates following a market rate shock are assumed to adjust based on the dynamic adjustment processes specified earlier and used to the estimate deposit premiums reported above. ${ }^{17}$

Because the deposit value equals initial deposits minus the value of deposit rents, the deposit value change is the negative of the change in the value of deposit rents. To illuminate important features of the deposit value's interest rate sensitivity, fix deposits at $\$ 1$ and let $V_{0}=1-\sum_{t=0}^{\infty} E^{Q}\left[\frac{\pi_{t}}{\beta_{t}}\right]$, with $\beta_{t}=e^{\int_{0}^{t} r_{\tau} d \tau}$ and $\pi_{t}$ the deposit rent at time $t$ (e.g., as defined in equation (4) (line 2)). Treating $\pi_{t}$ and $\beta_{t}$ as continuous functions of the initial market rate $r_{0}$, the deposit value change for a small initial rate shock is

$$
\frac{\partial V_{0 t}}{\partial r_{0}}=-\sum_{t=0}^{\infty} E^{Q}\left[\frac{1}{\beta_{t}}\left(\frac{\partial \pi_{t}}{\partial r_{0}}-\int_{0}^{t} \frac{\partial r(\tau)}{\partial r_{0}} d \tau\right)\right]
$$

(see Appendix A.1).

The term $\frac{1}{\beta_{t}} \frac{\partial \pi_{t}}{\partial r_{0}}$ in equation (8) captures the rent component's sensitivity to an initial market rate shock and $\frac{1}{\beta_{t}} \int_{0}^{t} \frac{\partial r(\tau)}{\partial r_{0}} d \tau$ captures the discounting component's sensitivity to a market rate shock. Assuming the expected value of the ratio $\frac{1}{\beta_{t}} \int_{0}^{t} \frac{\partial r(\tau)}{\partial r_{0}}$ is approximated by

\footnotetext{
${ }^{17}$ Thus, the interest rate elasticity and duration measures are not based on permanent market rate shocks and parallel shifts the yield curve; and the duration is not the same as Macaulay duration. For more detail, see CIR (1979) and Munk (1999). Hutchison and Pennacchi (1996) also use the CIR concept of duration.
} 
the ratio of expected values, the sensitivity of the market discount factor has the same sign as the market rate shock, which is positive since $E\left[\int_{0}^{t} \frac{\partial r(\tau)}{\partial r_{0}} d \tau\right]>0$. A positive market rate shock increases the discount factor which then increases the value of the deposit liability.

Without a model of both the market and deposit rate adjustments, the response of the rent to a market rate shock $\frac{\partial \pi_{t}}{\partial r_{0}}$ is ambiguous. In Appendix A.2, an analytic solution is developed for expected deposit rents at any future horizon, under both actual and risk-neutral processes. The solution holds for CIR and Vasicek market rate adjustment models and a symmetric deposit rate adjustment process in a continuous time setting. From an initial equilibrium where the actual market and deposit rates equal their respective unconditional expected values and with reasonable model parameters, there is a finite horizon $t^{*}>0$ such that $E\left[\frac{\partial \pi_{t}}{\partial r_{0}}\right]$ is positive for $0<t<t^{*}$, negative $t>t^{*}$, and approaches zero as $t \rightarrow \infty$.

Figure 6 illustrates this dynamics for market and deposit rates following a +200 basis point market rate shock. Model parameters are similar to those empirically estimated above (see Figure for details). The top left panel shows the dynamic adjustment of the expected market rate path, the top right panel the expected deposit rate adjustment, and the bottom panel the adjustment in the expected path of deposit rents (solid line) compared to the preshock expected rent path (dashed line). The aggregate change in expected rents is .036 from 0 to 6.5 years but only .016 from 0 to 100 years. The negative expected rent changes that emerge in the more distant future will moderate an overall negative interest rate elasticity of deposit values. The empirical significance of this is considered below.

Hutchison and Pennacchi (1996) noted that the interest rate sensitivity of expected future deposit rents and the market discount function have opposing effects (p. 411). However, they did not consider that the deposit rent interest rate sensitivity (in their model, as well as ours) changes sign at longer horizons.

\subsection{Interest Rate Risk Estimates}

For the baseline deposit values, market and deposit rates are initially at their long-term means and thus are consistent with the estimated premiums reported in the last section. Deposit value changes are estimated by resetting the initial market rate at levels ranging from +300 to -300 basis points from the initial rate at 50 basis point increments and 
recalculating the deposit values.

Interest rate elasticities for NOW accounts under fixed deposit balances are presented in Tables 6.a and 6.b. It is notable that the median elasticities are all less than 1 percent in absolute value and not more than 1.4 at the $10 \%$ quantile. Asymmetric deposit rate adjustment also creates asymmetry in the elasticities which are absolutely larger for deposit rate increases than for decreases. Under symmetric deposit rate adjustment, the elasticities are smaller than under asymmetric adjustment and at the $90 \%$ quantile are all positive, e.g., positive market rate shocks increase the bank's deposit liability. For reference, an annuity making fixed monthly payments in perpetuity would have an elasticity of approximately -2 percent under the market rate model used here (the elasticity of the annuity is independent of the level of the fixed monthly payments).

The NOW deposit durations for the banks with median interest rate elasticities under fixed balances that were reported in Tables 6.a and 6.b) are reported in the left panel of Table 6.c. Durations with variable deposits are reported in the right panel using a 360month rent horizon, even though the horizon was previously shown to be too short for variable deposits. The durations for median banks are mostly less than one year but exceed one year for market rate increases. Under variable deposits, the durations are not only smaller but are negative except for the positive rate shocks under asymmetric deposit rate adjustment (a positive interest rate elasticity is represented by a negative duration). For variable deposits the present values of the longer-term rent change reversals get relatively more weight due to growing deposits. For reference, the duration for an annuity with fixed monthly payments is approximately 4.3 years.

Interest rate elasticities and durations for MMDAs are presented in Tables 7.a, 7.b, and 7.c. Looking at the median durations in Table 7.c, they are all positive but fairly short, mostly 6 months or less. There is some duration asymmetry under the asymmetric deposit rate adjustment model. Under symmetric deposit rate adjustment, the median durations are shorter than under asymmetric adjustment.

To understand the effects of deposit rent dynamics on the interest rate risk estimates, the top panel in Figure 7 plots the expected monthly NOW account rents from horizons of 0 to 30 years pre-shock (solid line) and +200 basis point post-shock (dashed line) for the 
median bank. The bottom panel plots expected discounted pre- and post-shock rents. The reversal from positive expected rent changes in the early years to negative expected changes in the later years is obvious in the two panels.

The top panel in Figure 8 plots NOW and MMDA interest rate elasticities for $\mathrm{a}+200$ basis point shock for the two respective median banks. The elasticities are plotted for rent horizons truncated at lengths between 0 and 30 years. The elasticities absolute values first increase as the horizon is lengthened because the aggregate expected rent change is increasing. However, after several years (discounted) expected rent change become negative, beyond which further lengthening of the horizon results in smaller absolute interest rate elasticities. The last values in the NOW and MMDA plots (at 360 months) are the interest rate elasticities reported earlier in Tables 6.b and 7.b (row 4, col. 1). For comparison, an analogous plot in the bottom panel shows the interest rate elasticity for the annuity with fixed monthly payments in perpetuity. The elasticity declines throughout the 360month horizon, monotonically approaching the annuity's actual elasticity (over an unlimited horizon) of approximately -2 percent.

The CIR market rate model has a stationary unconditional mean (6.18 percent here) and rate shocks are transient. However, to illustrate potential effects of a permanent rate shock, consider an increase in both the initial and the mean market rate of 200 basis points. The top panel in Figure 9 plots the expected discounted monthly NOW rents for the median bank (the bank plotted Figure 7) before the shock (solid line) and after the shock (dotted line). The permanent shock increases expected discounted rents over a much longer horizon and there is no long-term rent undershoot. There is still some reversal in expected discounted rent changes due to the relative increase in the discount factor at long horizons.

Regarding interest rate risk estimates from previous studies, Hutchison and Pennacchi (1996) reported a median duration for NOW accounts of 6.7 years and about 4 months for MMDAs, using the same duration measure used here but with an analytical valuation model and different (but mean-reverting) market rate model. Janosi, Jarrow, and Zullo (1998) estimated a duration for NOW accounts of about 5 years, but based on a parallel shift in the forward rate curve (i.e., no mean reversion) and an analytical model. 


\subsection{Hedging Deposit Interest Rate Risk}

Interest rate risk for deposit values will be hedged if the bank's assets have the same durations as that for the deposit liabilities for a given interest rate shock. For NOW accounts and MMDAs, the durations estimated here are fairly small.

Short-term assets that hedge changes in deposit values due to interest rate shocks, however, will not hedge cash flow uncertainty associated with deposit liabilities. Assuming for simplicity that deposit balances are fixed, to hedge cash flow uncertainty a fund whose payoffs replicate the (market rate sensitive component of) deposit rates is needed. Accounting for asymmetric deposit rate adjustment, such a portfolio would require a set of interest rate call and put options so complex as to be unrealistic (see Appendix A.3).

Under symmetric adjustment, the market-rate sensitive component of a future deposit rate depends on the path of market rates up to that time. In Appendix A.3, the structure of forward interest rate positions that would hedge a sequence of future deposit rates, e.g., rates paid at times $t=2, \ldots, T$, are specified under the symmetric deposit rate adjustment model. These hedges would be consistent with floating rate assets but with (deterministic) time-varying positions in the floating rates. The position sizes are determined by the lag structure in the adjustment of the deposit rate to past market rates. In addition, the pathdependency implies that market-rate payments at each point in time would not match (the market rate sensitive component of) deposit rates paid at that time, with discrepancies producing a transient payments surplus/deficit.

The cash flow hedges as just described would not cover idiosyncratic changes in the deposit rates. Also, the hedges are only for a fixed level of deposits. Further, the structure of the hedges for the market rate sensitive component is correct only if the estimated deposit rate adjustment model is correct. That is, there is also model uncertainty.

\section{Conclusions}

The interest rate contingent claims model, with parsimonious autoregressions used for predicting future deposit rates and balances, provides a tractable framework for valuing transactions deposits. While the framework is tractable, its reliability will depend on the deposit rent process generated by the autoregressive modeling. The rent process and its 
implications for valuation and interest rate risk were studied here. Analysis and results were provided on a number of issues. These include the importance of asymmetry in deposit rate adjustment for estimated deposit values and interest rate risk, the length of the rent horizon for which forecasted deposit rents are important to the estimated deposit values, and the effects of deposit rate and market rate autoregressive dynamics on deposit rent dynamics and deposit interest rate risk.

With limited market price information on deposit accounts, evaluating the rent processes generated by assumed deposit rate and balances dynamics becomes particularly important. Were market prices available, the accuracy of model valuations could be directly tested or model parameters calibrated to the observed prices. While "core deposit premiums" are reported on bank and branch sales, it is not apparent that these premiums are closely related to the market value of the deposit liabilities per se.

Reported premiums represent the sale prices of target firms in excess of their tangible equity as a fraction of core deposits (deposits excluding large time deposits). As such, they would include the net value of any assets in excess of book value, the value of other (non-deposit) "intangibles," and the effects on premiums of non-competitive elements in the market for bank or branch acquisitions (see James and Weir (1987), and Berkovec, Mingo, and Zhang (1997)). Recent premiums on reported acquisitions would seem to reflect more than deposit rents due to paying below market interest rates. From 1990 to 1998, a period of declining market rates, core deposit premiums reported on private (non-failed) bank and branch sales rose substantially, as indicated in reports by SNL Securities (see Figure 10). Further, even if reported premiums are interpreted as deposit rent premiums, for valuation purposes it is still necessary to determine the breakdown for the different deposit categories, that include small time accounts as well as transactions deposits and savings accounts (see Berkovec and Liang (1991)).

Limited market price information may warrant more attention to modeling market structure factors and their the consequences for deposit values. In this context, there was substantial variation in the estimated NOW and MMDA premiums across banks. Further study of this cross-sectional variation may yield information on the importance of market structure factors to the estimated premiums. 


\section{References}

[1] Ausubel, Lawrence (1992). "Rigidity and Asymmetric Adjustment of Bank Interest Rates," manuscript, March.

[2] Berger, Allen and Timothy Hannan (1989). "The Price-Concentration Relationship in Banking," The Review of Economics and Statistics, May, pp. 291-299.

[3] Berkovec, James. and Nellie Liang (1991). "Deposit Premiums of Failed Banks: Implications for the Values of Deposits and Bank Franchises," Proceedings of a Conference on Bank Structure and Competition, Chicago Federal Reserve Bank, May, pp. 551-575.

[4] Berkovec, James, Mingo, John, and Xuechen Zhang (1997). "Premiums in Private versus Public Branch Sales," Finance and Economic Discussion Series, 97-33, Federal Reserve Board, June.

[5] Berlin, Mitchell and Loretta Mester (1999). "Deposits and Relationship Lending," The Review of Financial Studies, Fall, pp. 579-607.

[6] Chen, Ren-Raw and Louis Scott (1993). "Maximum Likelihood Estimation for a Multifactor Equilibrium Model of the Term Structure of Interest Rates," Journal of Fixed Income, December, pp. 14-31.

[7] Cox, John, Ingersoll, Jonathan, and Stephen Ross (1979). "Duration and the Measurement of Basis Risk," Journal of Business, Vol. 52, no.1, pp. 51-61

[8] Dueker, Michael (2000). "Are Prime rate changes Asymmetric?" Federal Reserve Bank of St. Louis Review, September /October, pp. 33-40.

[9] Duffie, Darrell (1996). Dynamic Asset Pricing, 2nd edition, Princeton NJ: Princeton University Press.

[10] Federal Reserve (1995). Risk-Based Capital Standards: Interest Rate Risk, Docket No. R-0802, August.

[11] Federal Reserve Functional Cost Annual Reports. various reports.

[12] Fisher, Mark and Christian Gilles (1996). "Risk Neutral Pricing and Risk Neutrality: A Tale of Two Equivalent Martingales," manuscript, October.

[13] Hawkins, Raymond and Michael Arnold (2000). "Relaxation processes in administeredrate pricing," Physical Review E, Vol. 62, October, pp. 4730-4736.

[14] Hannan, Timothy and Allen Berger (1991). "The Rigidity of Prices: Evidence from the Banking Industry," American Economic Review, Vol. 81, September, pp. 938-945.

[15] Hutchison, David and George Pennacchi (1996). "Measuring Rents and Interest Rate Risk in Imperfect Financial Markets: The Case of Retail Deposits," Journal of Financial and Quantitative Analysis, Vol. 31, September, pp. 399-417. 
[16] Hutchison, David (1995). "Retail Bank Deposit Pricing: An Intertemporal Asset Pricing Approach," Journal of Money, Credit, and Banking, Vol. 27, February, pp. 217-231.

[17] James, Christopher and Peggy Weir (1987). "Returns to Acquirers and Competition in the Acquisition Market: The case of Banking," Journal of Political Economy, Vol. 95, no. 21, pp. 355-370.

[18] Janosi, Tibor, Jarrow, Robert, and Ferdinando Zullo (1999). "An Empirical Analysis of the Jarrow-van Deventer Model for Valuing Non-Maturity Deposits," Journal of Derivatives, Vol. 7, Fall, pp. 8-31.

[19] Jarrow, Robert and Donald van Deventer (1998). "The arbitrage-free valuation and hedging of demand deposits and credit card loans," Journal of Banking and Finance, Vol. 22, pp. 249-272.

[20] Kahn, Charles, Pennacchi, George, and Ben Sopranzetti (1999). "Bank Deposit Clustering: Theory and Empirical Evidence," Journal of Finance, Vol. 54, Dec., 2185-2214.

[21] Moore, George, Porter, Richard, and David Small (1990). "Modeling the Disaggregated Demands for M2 and M1: The U.S. Experience in the 1980s," Board of Governors of the Federal Reserve System.

[22] Munk, Claus, "Stochastic Duration and Fast Coupon Bond Option Pricing in MultiFactor Models," Review of Derivatives Research, (1999) Vol. 3, pp. 157-181.

[23] Neumark, David and Stephen Sharpe (1992). "Market Structure and the Nature of Price Rigidity," Quarterly Journal of Economics, Vol. 429, May, pp. 657-680.

[24] O'Brien, James, Orphanides, Athanasios, and David Small (1994). "Estimating the Interest Rate Sensitivity of Liquid Retail Deposits," Proceedings of a Conference on Bank Structure and Competition, Chicago Federal Reserve Bank, May, pp. 400-435.

[25] Office of Thrift Supervision (1994). "The OTS Net Portfolio Value Model."

[26] Pennacchi, George (1999), "The Value of Guarantees on Pension Fund Returns," The Journal of Risk and Insurance, Vol. 66, No. 2, pp. 219-237.

[27] Selvaggio, Robert (1996). "Using the OAS Methodology to Value and Hedge Commercial Bank Retail Demand Deposit Premiums," Handbook of Asset/liability Management, Frank Fabbozi and Atsuo Knoishi, eds, pp. 363-373.

[28] Sharpe, Stephen (1997). "The Effect of Consumer Switching Costs on Prices: A Theory and its Application to the Bank Deposit Market," Review of Industrial Organization, Vol. 12, pp. 79-94.

[29] SNL Securities, Bank Mergers and Acquisitions, Charlottesville, VA, various issues.

[30] Whitesell, William (1992). "Deposit Banks and the Market for Payment Media," Journal of Money, Credit, and Banking, Vol. 24, November, pp. 483-498. 


\section{Appendix}

\section{A.1 Deposit Value Interest Rate Sensitivity}

The interest rate sensitivity of the value of the deposit liability expressed in equation (8) is determined as follows:

$$
\begin{aligned}
\frac{\partial V_{0 t}}{\partial r_{0}} & =-\sum_{t=0}^{\infty} \frac{\partial}{\partial r_{0}} E^{Q}\left[\frac{\pi_{t}}{\beta_{t}}\right] \\
& =-\sum_{t=0}^{\infty} E^{Q}\left[\frac{1}{\beta_{t}}\left(\frac{\partial \pi_{t}}{\partial r_{0}}-\frac{1}{\beta_{t}} \frac{\partial \beta_{t}}{\partial r_{0}}\right)\right] \\
& =-\sum_{t=0}^{\infty} E^{Q}\left[\frac{1}{\beta_{t}}\left(\frac{\partial \pi_{t}}{\partial r_{0}}-\int_{0}^{t} \frac{\partial r(\tau)}{\partial r_{0}} d \tau\right)\right]
\end{aligned}
$$

\section{A.2 Expected Deposit Rate and Rent Dynamics}

The expected deposit rate and profit are derived assuming a risk-free market rate that satisfies the 1-factor Vasicek or CIR stochastic processes. The Vasicek and CIR models, under either the actual or risk-neutral processes, have the general forms

$$
\begin{array}{llrl}
d r_{t}=\left(\alpha-\gamma r_{t}\right) d t+\sigma d z_{t} & (\text { Vasicek) } \\
d r_{t}=\left(\alpha-\gamma r_{t}\right) d t+r_{t}^{.5} \sigma d z_{t} & (\mathrm{CIR})
\end{array}
$$

where $z_{t}$ is a Wiener process.

While the functional form is the same, the derivations of the two equations, and their respective derivations under the actual and risk neutral processes, are different. Further, under the risk neutral process, $r_{t}$ and $z_{t}$ should be interpreted as values under that process. For purposes here, these differences are immaterial. Given an initial rate, $r_{0}$, for either model and under the actual or risk-neutral processes, the expected future market rate has the form

$$
E\left[r_{t}\right]=\frac{\alpha}{\gamma}+\left(r_{0}-\frac{\alpha}{\gamma}\right) e^{-\gamma t}
$$

The continuous time process for the deposit rate, $R_{t}$, is given by

$$
d R_{t}=\eta\left(b r_{t}-g-R_{t}\right) d t+\psi d w_{t}
$$


where $w_{t}$ is a Wiener process. To determine a solution, apply the integrating factor $e^{\eta t}$ to equation (A-4) to get

$$
e^{\eta t}\left(d R_{t}+\eta R_{t} d t\right)=e^{\eta t} \eta\left(b r_{t}-g\right) d t+e^{\eta t} \psi d w_{t}
$$

Using Ito's lemma,

$$
\begin{aligned}
d\left(e^{\eta t} R_{t}\right) & =\eta e^{\eta t} R_{t} d t+e^{\eta t} d R_{t}+\frac{1}{2} \frac{\partial^{2}\left(e^{\eta t} R_{t}\right)}{\partial R_{t}^{2}}\left(d R_{t}\right)^{2} \\
& =e^{\eta t}\left(d R_{t}+\eta R_{t} d t\right)
\end{aligned}
$$

Integrating both sides of (A-5) and using (A-6) gives

$$
e^{\eta t} R_{t}=\int_{0}^{t} e^{\eta s} \eta\left(b r_{s}-g\right) d s+\int_{0}^{t} e^{\eta s} \psi d w_{s}+R_{0}
$$

and

$$
R_{t}=\int_{0}^{t} e^{\eta(s-t)} \eta\left(b r_{s}-g\right) d s+\int_{0}^{t} e^{\eta(s-t)} \psi d w_{s}+e^{-\eta t} R_{0}
$$

where $R_{0}$, the initial deposit rate, is the constant of integration.

To find the expectation of $R_{t}$ when $\eta \neq \gamma$, take the expectation of (A-7):

$$
\begin{aligned}
E\left[R_{t}\right] & =\int_{0}^{t} e^{\eta(s-t)} \eta\left(b E\left[r_{s}\right]-g\right) d s+e^{-\eta t} R_{0} \\
& =\int_{0}^{t} e^{\eta(s-t)} \eta\left(b\left(\frac{\alpha}{\gamma}+\left(r_{0}-\frac{\alpha}{\gamma}\right) e^{-\gamma(s-t)}\right)-g\right) d s+e^{-\eta t} R_{0} \\
& =\int_{0}^{t} e^{\eta(s-t)} \eta\left(b \frac{\alpha}{\gamma}-g\right) d s+\int_{0}^{t} e^{(\eta-\gamma)(s-t)} \eta b\left(r_{0}-\frac{\alpha}{\gamma}\right) d s+e^{-\eta t} R_{0} \\
& =\left.\left(b \frac{\alpha}{\gamma}-g\right) e^{\eta(s-t)}\right|_{0} ^{t}+\left.\frac{\eta}{\eta-\gamma} b\left(r_{0}-\frac{\alpha}{\gamma}\right) e^{(\eta-\gamma)(s-t)}\right|_{0} ^{t}+e^{-\eta t} R_{0} \\
& =\left(b \frac{\alpha}{\gamma}-g\right)\left(1-e^{-\eta t}\right)+\frac{\eta}{\eta-\gamma} b\left(r_{0}-\frac{\alpha}{\gamma}\right)\left(e^{-\gamma t}-e^{-\eta t}\right)+e^{-\eta t} R_{0} \\
& =b \frac{\alpha}{\gamma}-g+\left(R_{0}-\left(b \frac{\alpha}{\gamma}-g\right)\right) e^{-\eta t}+\frac{\eta}{\eta-\gamma} b\left(r_{0}-\frac{\alpha}{\gamma}\right)\left(e^{-\gamma t}-e^{-\eta t}\right)
\end{aligned}
$$

If $\eta=\gamma$,

$$
E\left[R_{t}\right]=b \frac{\alpha}{\gamma}-g+\left(R_{0}-\left(b \frac{\alpha}{\gamma}-g\right)\right) e^{-\gamma t}+\gamma b\left(r_{0}-\frac{\alpha}{\gamma}\right) t e^{-\gamma t}
$$


Now consider the bank's expected deposit rent at time $t$, given $r_{0}$ and $R_{0}$ and setting deposits equal to $\$ 1$. The rent is assumed to have the linear form: $\pi_{t}=B r_{t}-C-R_{t}$. The deposit rent is also assumed to be non-negative when the deposit rate is at its equilibrium $b r_{t}-g$ (see (A.4)). Specifically, let $B \geq b>0$. The expected rent at time $t$, given $r_{0}$ and $R_{0}$, is obtained using (A-3), (A-8) and (A-9). For $\eta \neq \gamma$

$$
\begin{aligned}
E\left[\pi_{t} \mid r_{0}, R_{0}\right]= & B E\left[r_{t} \mid r_{0}\right]-C-E\left[R_{t} \mid r_{0}, R_{0}\right] \\
= & B \frac{\alpha}{\gamma}+B\left(r_{0}-\frac{\alpha}{\gamma}\right) e^{-\gamma t}-g-\left(b \frac{\alpha}{\gamma}-g+\left(R_{0}-\left(b \frac{\alpha}{\gamma}-g\right)\right) e^{-\eta t}\right. \\
& \left.+\frac{\eta}{\eta-\gamma} b\left(r_{0}-\frac{\alpha}{\gamma}\right)\left(e^{-\gamma t}-e^{-\eta t}\right)\right) \\
= & (B-b) \frac{\alpha}{\gamma}+(g-C)+B\left(r_{0}-\frac{\alpha}{\gamma}\right) e^{-\gamma t}+\left(b \frac{\alpha}{\gamma}-g-R_{0}\right) e^{-\eta t} \\
& +\frac{\eta}{\eta-\gamma} b\left(\frac{\alpha}{\gamma}-r_{0}\right)\left(e^{-\gamma t}-e^{-\eta t}\right)
\end{aligned}
$$

For $\eta=\gamma$

$E\left[\pi_{t} \mid r_{0}, R_{0}\right]=(B-b) \frac{\alpha}{\gamma}+(g-C)+B\left(r_{0}-\frac{\alpha}{\gamma}\right) e^{-\gamma t}+\left(b \frac{\alpha}{\gamma}-g-R_{0}\right) e^{-\gamma t}-\gamma b\left(r_{0}-\frac{\alpha}{\gamma}\right) t e^{-\gamma t}$ For $\frac{\partial E\left[\pi_{t}\right]}{\partial r_{0}}$, we get

$$
\begin{aligned}
\frac{\partial E\left[\pi_{t}\right]}{\partial r_{0}} & =B e^{-\gamma t}-\frac{\eta b}{\eta-\gamma}\left(e^{-\gamma t}-e^{-\eta t}\right) & & \text { for } \eta \neq \gamma \\
& =B e^{-\gamma t}-\gamma b t e^{-\gamma t} & & \text { for } \eta=\gamma
\end{aligned}
$$

This derivative will have a value of zero for $t=t^{*}$, where

$$
\begin{aligned}
t^{*} & =\ln \left[\frac{B(\gamma-\eta)}{b \gamma}+1\right] \frac{1}{\gamma-\eta} & & \text { for } \eta \neq \gamma \\
& =\frac{B}{b \gamma} & & \text { for } \eta=\gamma
\end{aligned}
$$

First note that at $t=0, \frac{\partial E\left[\pi_{t}\right]}{\partial r_{0}}=B>0$ in both (A-10) and (A-11). Next, for $B \geq b$ and $\gamma \geq \eta$ (i.e., deposit rates do not adjust faster than market rates), there is a positive finite horizon, $t^{*}$ where $\frac{\partial E\left[\pi_{t}\right]}{\partial r_{0}}=0$. Further, if these conditions are satisfied, then between 0 and $t^{*}, \frac{\partial E\left[\pi_{t}\right]}{\partial r_{0}}>0$ and, between $t^{*}$ and $\infty, \frac{\partial E\left[\pi_{t}\right]}{\partial r_{0}}<0$ but asymptotically approaches $0 .{ }^{18}$ In sum, a shock to the market rate produces an expected rent change in the same direction for $t<t^{*}$ and in the opposite direction for $t>t^{*}$.

\footnotetext{
${ }^{18}$ To see this, evaluate the derivative at $t^{*}+\Delta$ for $\Delta<0$ and $\Delta>0$.
} 


\section{A.3 Hedging Cash Flow Risk}

The deposit rate adjustment equation expressed in equation (1) is

$$
\Delta R_{t}=\left(\lambda^{+} I_{t}+\lambda^{-}\left(1-I_{t}\right)\right)\left(b r_{t}-g-R_{t-1}\right)+e_{t}
$$

Rewrite, $I_{t}\left(b r_{t}-g-R_{t-1}\right)=\max \left\{b r_{t}-g-R_{t-1}, 0\right\}$, and $\left.\left(1-I_{t}\right)\right)\left(b r_{t}-g-R_{t-1}\right)=$ $-\max \left\{R_{t-1}+g-b r_{t}, 0\right\}$. With repeated substitution,

$$
R_{t}=R_{0}+\Sigma_{s=1}^{t}\left(\lambda^{+} \max \left\{b r_{s}-g-R_{s-1}, 0\right\}-\lambda^{-} \max \left\{R_{s-1}+g-b r_{t}, 0\right\}+e_{s}\right)
$$

If $\lambda^{+}=\lambda^{-}$,

$$
R_{t}=R_{0}(1-\lambda)^{t}-\lambda \sum_{s=1}^{t}(1-\lambda)^{t-s} g+\lambda \sum_{s=1}^{t}(1-\lambda)^{t-s} b r_{s}+\sum_{s=1}^{t}(1-\lambda)^{t-s} e_{s}
$$

Fix deposits at $\$ 1$. From both (A-15) and (A-16), deposit payment cash flow uncertainty comes for two additive components: future market rates and idiosyncratic shocks. Under asymmetric deposit rate adjustment, (A-15), hedging the market rate component is extremely complex. It involves complex interest rate puts and calls and a complete hedging strategy for cash flow risk would be unrealistic.

Under symmetric deposit rate adjustment, the market rate component can be hedged with a series of long forward contracts (or a pay fixed - receive floating interest rate swap). This is consistent with suggestions by Jarrow and van Deventer (1998). However, the deposit rate paid at time $t$ is dependent on the path of market rates up to $t$ and, further, the forward rate positions would vary over the different delivery horizons. To hedge this market rate component at time 0 , the bank would take long forward positions in the 1-period market rate set at $s-1$ of size $(1-\lambda)^{t-s} b$ for delivery at times $s=2, \ldots, t$. If the bank were to hedge at time 0 all deposit rate interest rate payments up to time $T$, the bank would need forward contracts delivered at times $s=2, \ldots, T$ in amounts $(T+1-s) b \lambda(1-\tau)^{s-1}$. These positions would result in a reserve being built up to cover future deposit payments (the market rate component) and subsequently run-off. ${ }^{19}$

\footnotetext{
${ }^{19}$ This assumes that the reserve is held in cash. Smaller positions would be needed if the reserve was invested in risk-free bonds.
} 


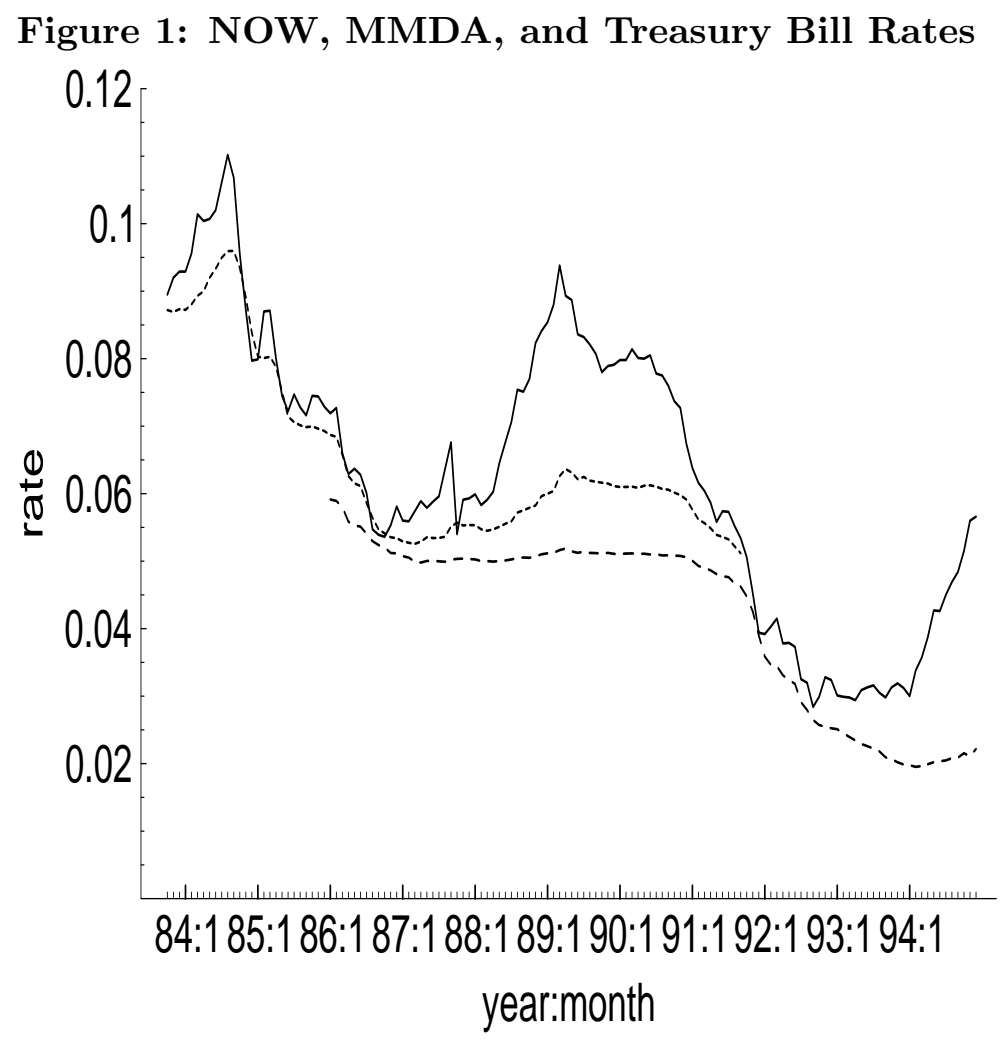

Solid line: 3-month Treasury rate. Dotted line: MMDA rate. Dashed line: NOW rate. NOW and MMDA rates are average rates for sample banks used in study. The two deposit rate series start at their respective full de-regulation dates and the MMDA series ends with the last month for which MMDA rates were reported separately. While NOW rates continue to be reported, for the study, the series was ended in Dec. 1994 because of the distortion of reported NOW deposits due to "sweeps" (see text, footnote 4, p.7). Data source: Federal Reserve monthly report forms FR 2042. 
Figure 2: Simulated Market, NOW and MMDA Rates
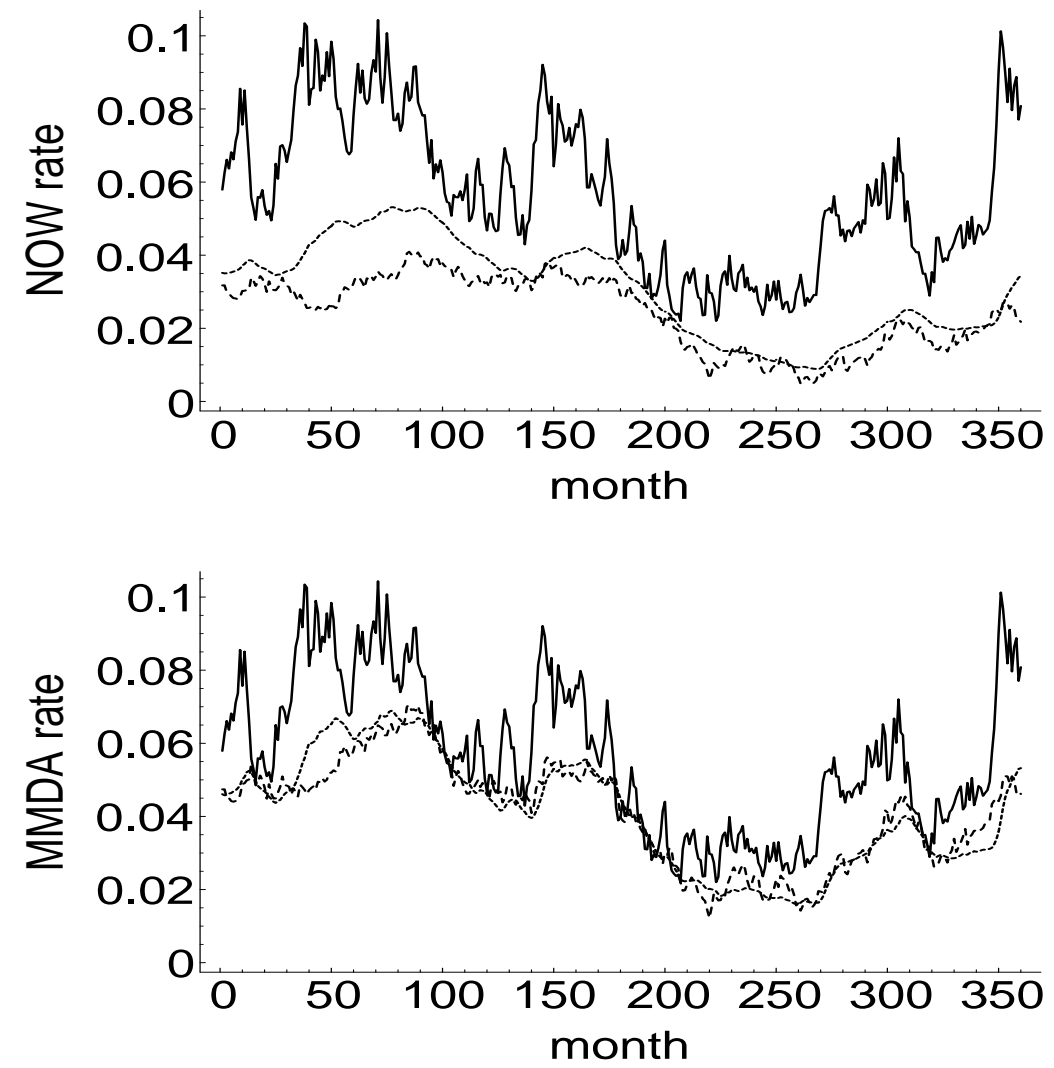

Solid line: simulated market rate over 360-month horizon. Dashed line: simulated averagebank deposit rate under asymmetric adjustment. Dotted line: simulated average-bank deposit rate under symmetric adjustment. Deposit rate simulations are averages of each bank's deposit rate forecast. 
Figure 3: Simulated NOW and MMDA Log Deposits
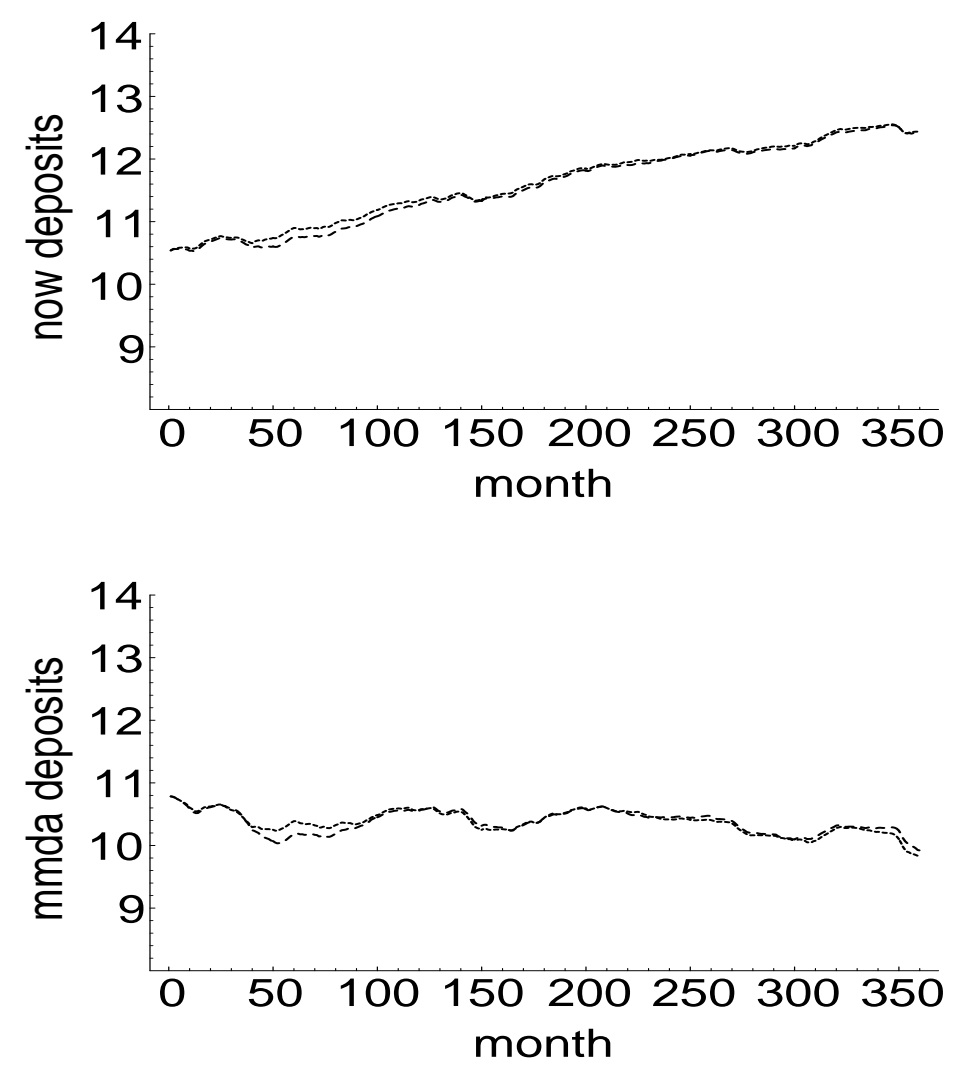

Dashed lines: simulated average-bank log deposits with asymmetric deposit rate adjustment. Dotted line: simulated average-bank log deposits under symmetric deposit rate adjustment. Simulations use deposit rates simulated in Figure 2. Simulations are averages of each bank's deposit balances forecasts. 
Figure 4: NOW Premiums by Horizon
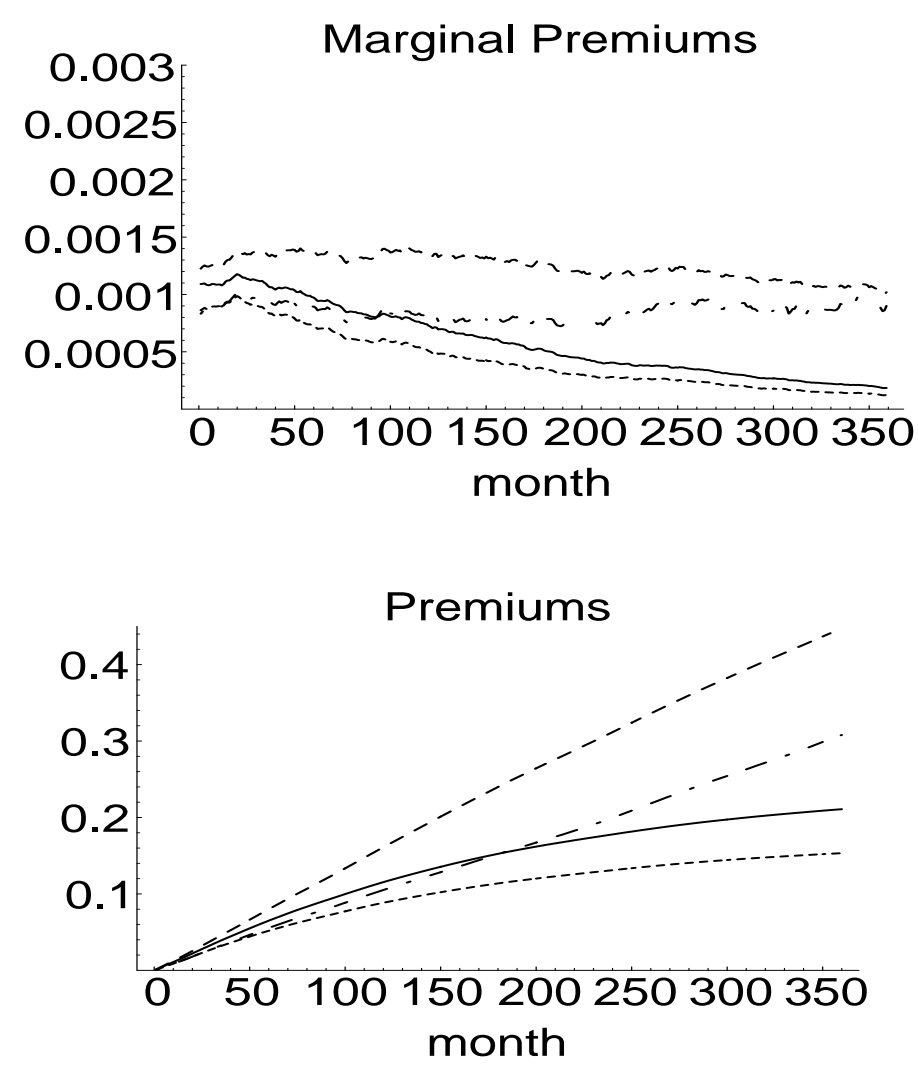

Top and bottom panel premiums expressed per-dollar of initial deposits. Top panel: monthly marginal premiums, i.e., expected monthly discounted rents. solid line: asymmetric adjustment, fixed deposits; dotted line: symmetric adjustment, fixed deposits; dashed line: asymmetric adjustment, variable deposits; dash-dot: symmetric adjustment, variable deposits. Bottom panel: now premiums (aggregate of marginal premiums) with cumulative discounted rents truncated at horizons from 0 to 360 months. Plot styles correspond to top panel. 
Figure 5: MMDA Premiums by Horizon
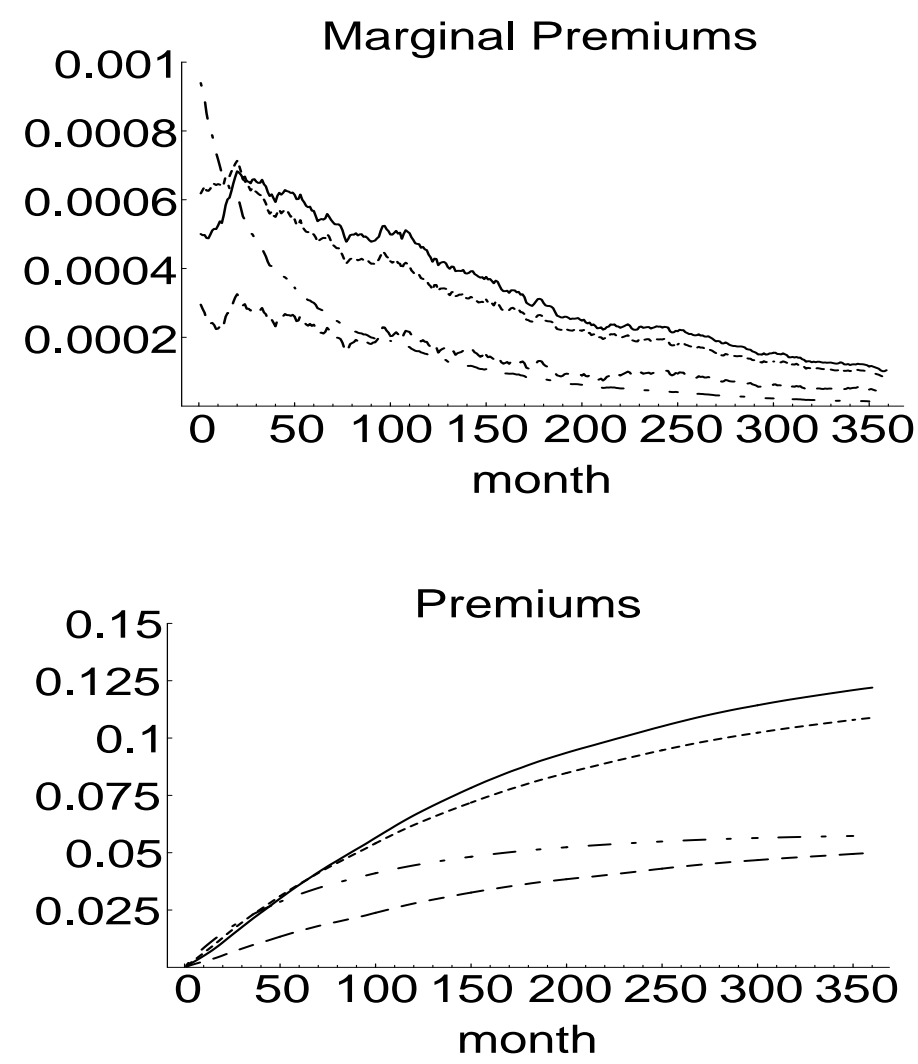

Top and bottom panel premiums expressed per-dollar of initial deposits. Top panel: marginal premiums,i.e., expected monthly discounted rents. solid line: asymmetric adjustment, fixed deposits; dotted line: symmetric adjustment, fixed deposits; dashed line: asymmetric adjustment, variable deposits; dash-dot: symmetric adjustment, variable deposits. Bottom panel: MMDA premiums (aggregate of marginal premiums) with cumulative discounted rents truncated at horizons from 0 to 360 months. Plot styles correspond to top panel. 
Figure 6: Illustrated Expected Rent Dynamics
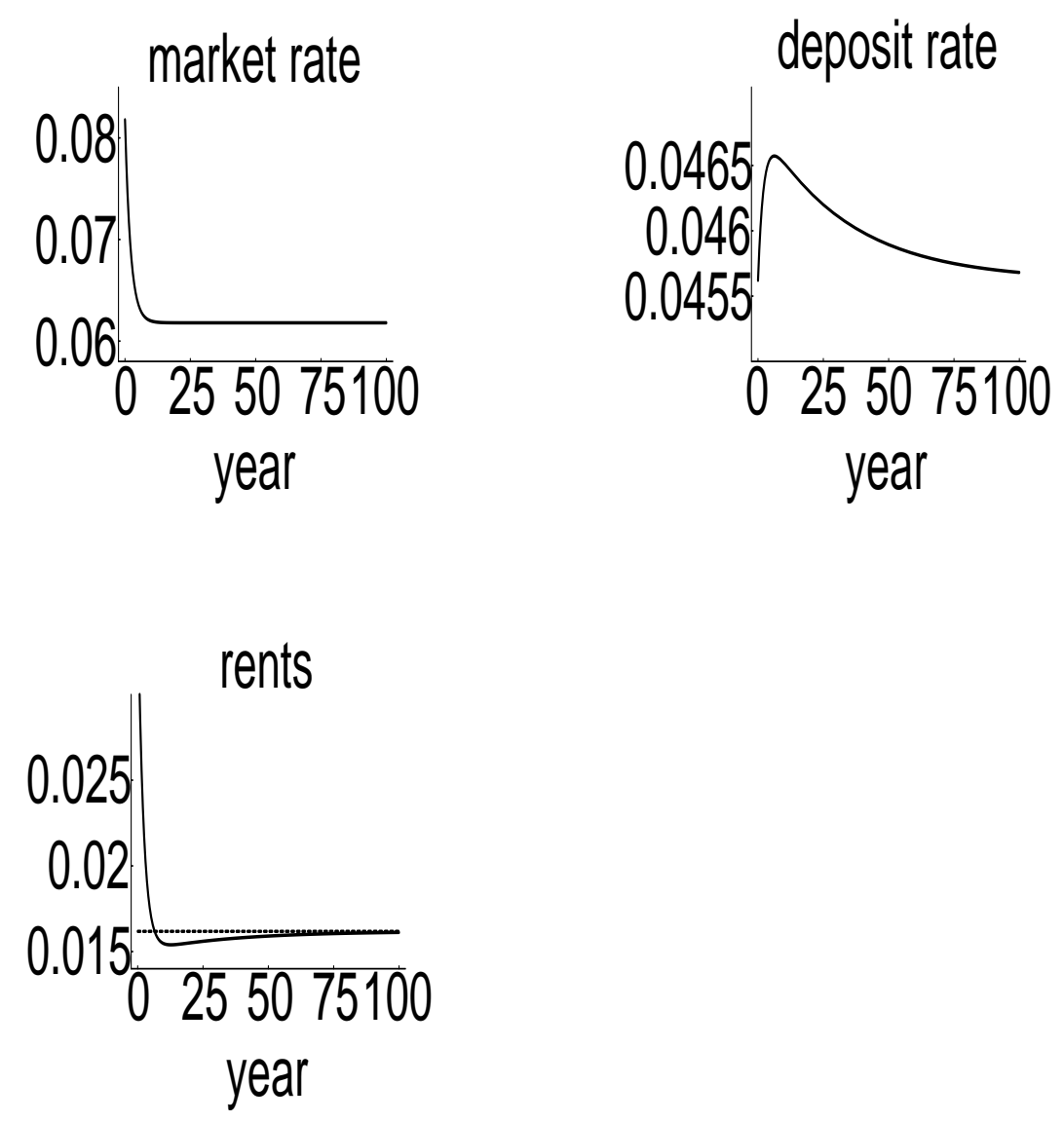

Dynamics following +200 basis point shock to market rate. Top panels: expected market rate dynamics, and expected deposit rate dynamics. Bottom panel: expected deposit rents following rate shock (solid line) and prior to rate shock (dashed line). Also, see Appendix A.2. Parameter values: $\alpha=.029 ; \gamma=.47 ; \eta=.03 ; b=.9 ; g=.03 ; r_{0}=.0818, E\left[r_{t}\right]=.0618 ; R_{0}=E\left[R_{t}\right]=$ 0456. 
Figure 7: NOW Rents by Horizon
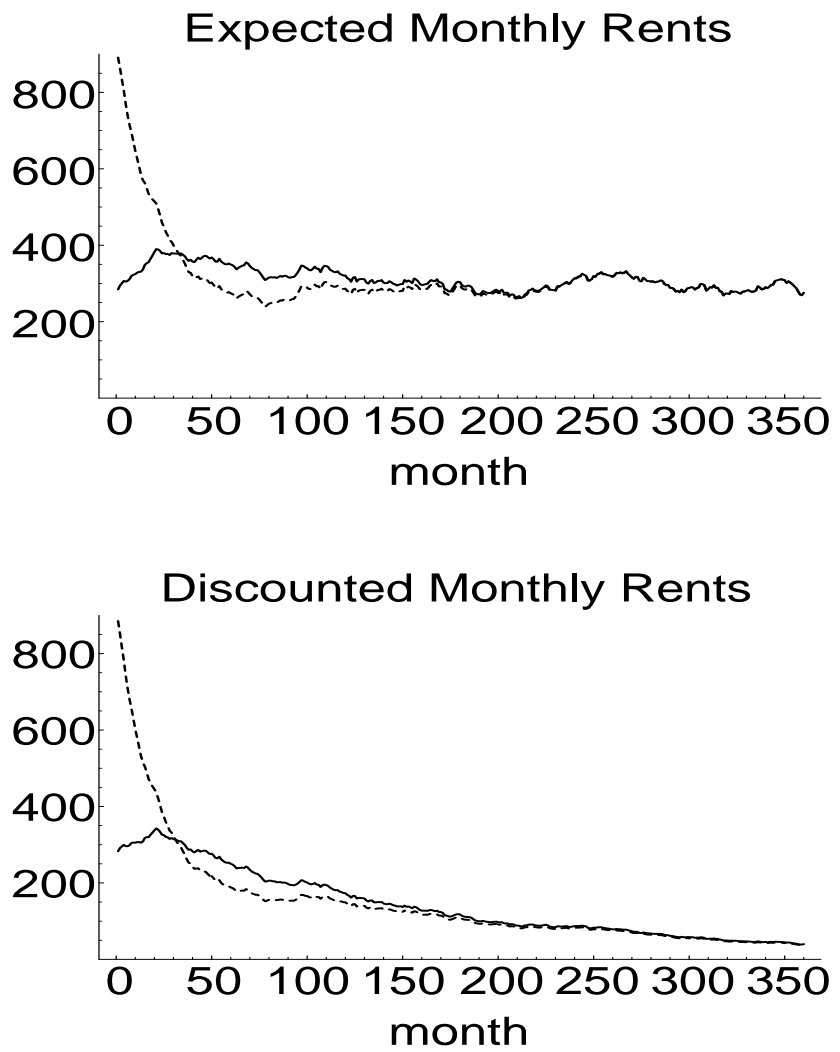

Rents measured in thousands of dollars for the median bank under symmetric deposit rate adjustment and fixed deposits. Top panel: solid line is base simulation for expected monthly rents; dotted line is expected rents after market rate shock of +200 basis points. Bottom panel: expected discounted monthly rents for base simulation and for after market rate shock. Plot styles follow top panel. 
Figure 8: NOW, MMDA and Annuity Interest Rate Elasticities by Horizon
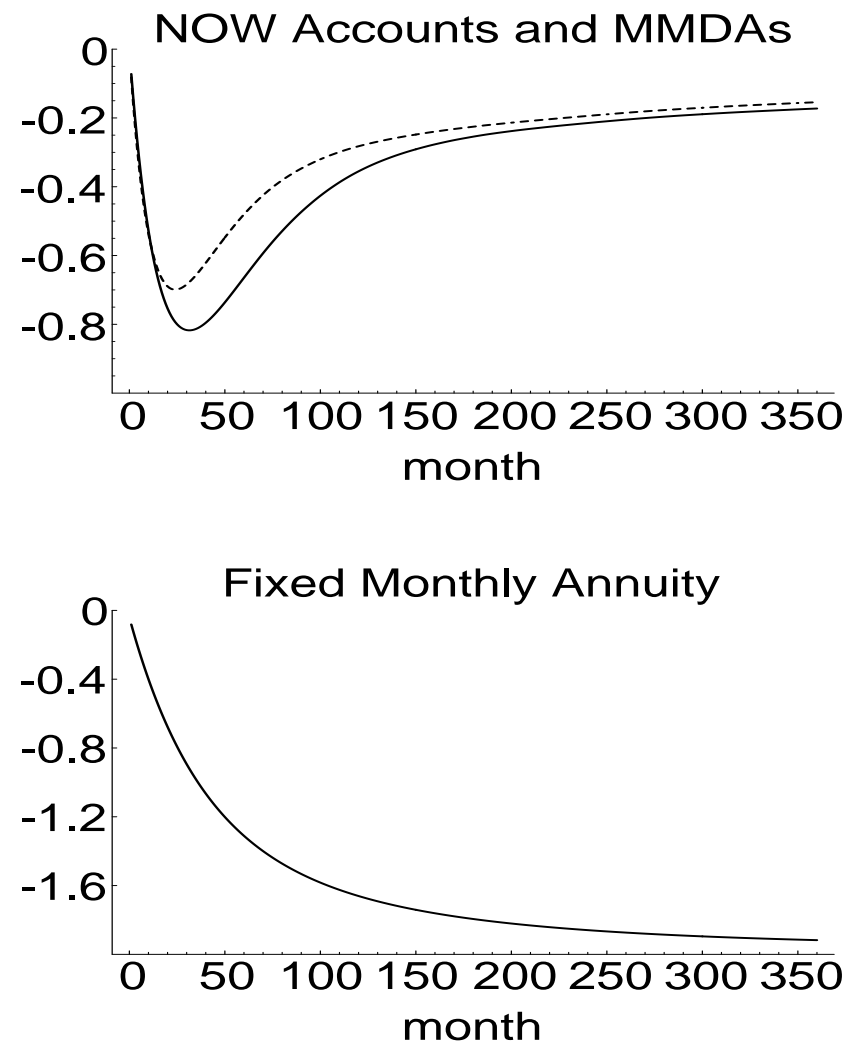

Elasticities measured in percentage points. Top panel: NOW (solid line) and MMDA (dotted line) interest rate elasticities for respective median banks under symmetric deposit rate adjustment and fixed deposits with cumulative rents truncated at horizons from 0 to 360 months. Market rate is shifted +200 basis points. Interest rate elasticity is per 100 basis points. Bottom panel: Interest rate elasticities for annuity paying a fixed monthly rate. 
Figure 9: NOW Rents and Elasticity Permanent Shock
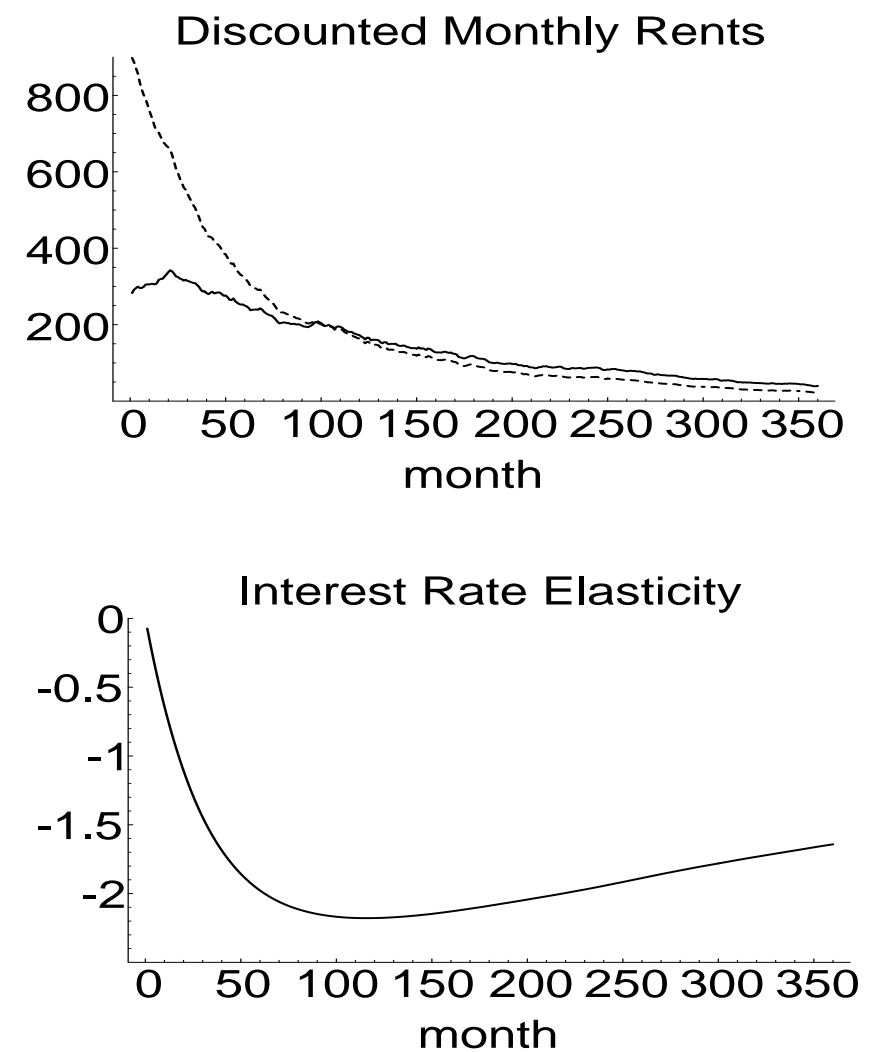

Rents measured in thousands of dollars. Elasticities measured in percentage points. For bank with median elasticity under symmetric deposit rate adjustment and fixed deposits (used in Figures 6 and 7. Market rate and mean of process is shifted 200 basis points. Top panel: solid line: base simulation expected discounted rents; dotted line discounted rents after permanent market rate shock. Bottom panel: interest rate elasticity with cumulative rents truncated at horizons from 0 and 360 months. Interest rate elasticity is per 100 basis points. 
Figure 10: Core Deposit Premiums and T-Bill Rates: 1990-1998

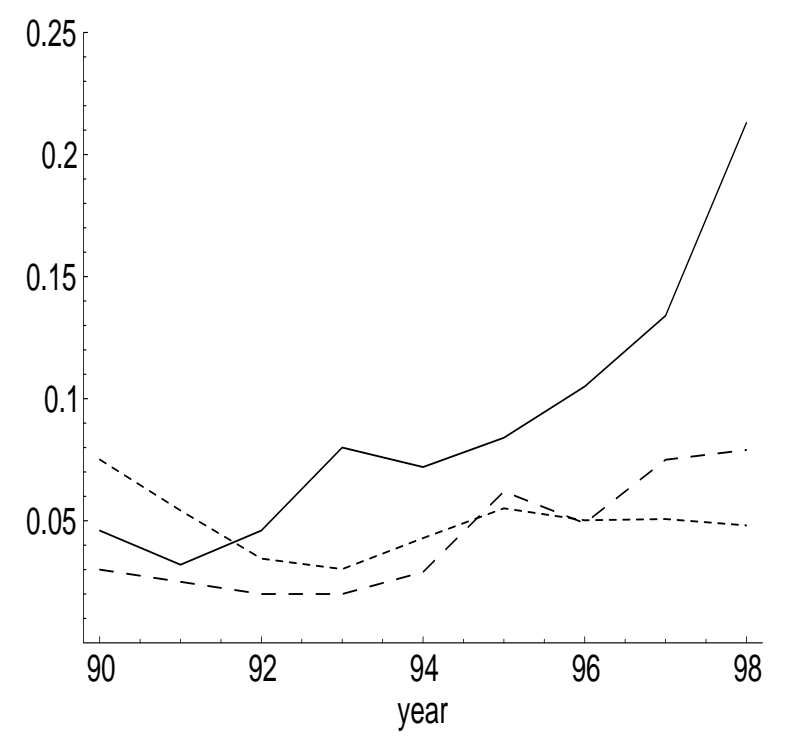

Median values of annual core deposit premiums. Solid line: bank acquisitions; dashed line: branch sales; dotted line: 3-mo. t-bill rate. Core deposit premiums source: SNL Securities, Bank Mergers and Acquisitions, various issues. 
Table 1: Bank Sample Deposit Rates and Balances ${ }^{a}$

\begin{tabular}{|c|c|c|c|c|c|c|c|c|}
\hline & \multicolumn{4}{|c|}{ NOW Accts } & \multicolumn{4}{|c|}{ MMDAs } \\
\hline remaining sample & & ave & ave & med & & ave & ave & med \\
\hline after deletions & size & rate & bal & bal & size & rate & bal & bal \\
\hline initial sample $^{b}$ & 160 & .0423 & 175.8 & 31.6 & 160 & .0652 & 289.7 & 38.6 \\
\hline due to deposit balances ${ }^{c}$ & 135 & .0421 & 232.2 & 36.9 & 135 & .0650 & 410.6 & 44.7 \\
\hline due to initial value ${ }^{d}$ & 99 & .0419 & 249.7 & 47.9 & 99 & .0649 & 398.9 & 49.0 \\
\hline due to non-stationarity ${ }^{e}$ & 74 & .0419 & 263.7 & 48.7 & 95 & .0650 & 407.8 & 58.5 \\
\hline
\end{tabular}

\footnotetext{
${ }^{a}$ For each sample and deposit type, the reported average is taken over the entire panel (i.e., over time and across banks). The reported median is for the medians of the individual banks' time series. Deposit balances data are in millions of dollars. Deposit rate and balances data are from the Federal Reserve reports FR2042: Monthly Survey of selected deposits and Other Accounts from Jan 1986 to Dec 1994 (NOW accounts) and Nov 1983 to Sept 1991 (MMDAs).

${ }^{b}$ All banks that had complete data sets over the sample period

${ }^{c}$ Banks dropped due to erratic deposit balances.

${ }^{d}$ Banks dropped due to parameter sensitivity to initial values in applying non-linear least squares to deposit rate adjustment equation.

${ }^{e}$ Banks dropped due to non-stationarity in estimated asymmetric deposit rate adjustment equation.
} 
Table 2: NOW Rate Adjustment Estimates ${ }^{a}$

\begin{tabular}{|c|c|c|c|c|c|c|}
\hline & \multicolumn{3}{|c|}{$\Delta R_{i t}=\left(\lambda_{i}^{+} I_{i t}+\lambda_{i}^{-}\left(1-I_{i t}\right)\right)\left(b_{i} r_{t}-g_{i}-R_{i t-1}\right)+e_{i t}$} & & \multicolumn{2}{|c|}{ deposit rate averages $b$} \\
\hline & $\lambda_{i}^{+}$ & $\lambda_{i}^{-}$ & $b_{i}$ & $g_{i}$ & $\overline{R_{i t}}$ & $\overline{R_{i t}^{e}}$ \\
\hline & \multicolumn{6}{|c|}{ A. Asymmetric Adjustment } \\
\hline mean & $.057^{c}$ & .439 & 1.039 & .010 & .0419 & .0499 \\
\hline median & .002 & .293 & 1.023 & .011 & .0420 & .0499 \\
\hline 10\% Quantile & -.002 & .082 & .717 & -.006 & .0397 & .0459 \\
\hline 90\% Quantile & .025 & .790 & 1.341 & .025 & .0439 & .0543 \\
\hline mean t-stat & .281 & 4.145 & $16.729^{d}$ & 2.595 & & \\
\hline num sig at $.05^{e}$ & 3 & 94 & 97 & $62^{f}$ & & \\
\hline \multirow[t]{2}{*}{ num sig at .01 } & 0 & 85 & 80 & 57 & & \\
\hline & \multicolumn{6}{|c|}{ B. Symmetric Adjustment $\left(\lambda_{i}^{+}=\lambda_{i}^{-}\right)$} \\
\hline mean & & .041 & .918 & .023 & .0419 & .0297 \\
\hline median & & .034 & .890 & .021 & .0420 & .0304 \\
\hline 10\% Quantile & & .021 & .586 & -.002 & .0397 & .0256 \\
\hline $90 \%$ Quantile & & .064 & 1.301 & .048 & .0439 & .0343 \\
\hline mean t-stat & & 3.135 & 4.827 & 1.245 & & \\
\hline median t-stat & & 3.148 & 4.622 & 1.284 & & \\
\hline num sig at .05 & & 88 & 96 & 23 & & \\
\hline num sig at .01 & & 69 & 91 & 8 & & \\
\hline \multicolumn{7}{|c|}{\begin{tabular}{ll} 
Tests for Symmetric Adjustment \\
\cline { 2 - 2 }
\end{tabular}} \\
\hline \multicolumn{4}{|c|}{ t-stat: $\lambda^{+}-\lambda^{-}$} & \multicolumn{3}{|c|}{$\chi^{2}: T\left(\log \left(s s e_{r} / T\right)-\log \left(s_{s e} / T\right)\right)$} \\
\hline \multicolumn{4}{|c|}{ mean: -3.805} & \multicolumn{3}{|c|}{ mean: 26.636} \\
\hline \multicolumn{4}{|c|}{ median: -3.908 } & \multicolumn{3}{|c|}{ median: 19.271} \\
\hline \multicolumn{4}{|c|}{ num $\leq-2.35^{g}: 82$} & \multicolumn{3}{|c|}{ num $\geq 6.63^{h}: 85$} \\
\hline
\end{tabular}

${ }^{a}$ Estimation period: 1986(1) - 1994(12). Average T-bill rate $=.0574$. Sample: 99 banks.

${ }^{b}$ Averages over banks and sample period.

${ }^{c}$ Mean reflects several outlier values.

${ }^{d}$ For $H_{o}=1$, mean t-stat is .055

${ }^{e}$-sided test for $H_{o}=0$

${ }^{f}$ For $g, 52$ of 62 significant coefficients positive.

${ }^{g} \operatorname{prob}(\mathrm{t} \leq-2.35)=.01$

${ }^{h} \operatorname{prob}\left(\chi^{2} \geq 6.63\right)=.01$ 
Table 3: MMDA Rate Adjustment Estimates ${ }^{a}$

\begin{tabular}{|c|c|c|c|c|c|c|}
\hline \multicolumn{7}{|c|}{$\frac{\Delta R_{i t}=\left(\lambda_{i}^{+} I_{i t}+\lambda_{i}^{-}\left(1-I_{i t}\right)\right)\left(b_{i} r_{t}-g_{i}-R_{i t-1}\right)+e_{i t}}{\text { parameter estimates }}$ deposit rate averages ${ }^{b}$} \\
\hline & $\lambda_{i}^{+}$ & $\lambda_{i}^{-}$ & $b_{i}$ & $g_{i}$ & $\overline{R_{i t}}$ & $\bar{R}_{i t}^{e}$ \\
\hline \multicolumn{7}{|c|}{ A. Asymmetric Adjustment } \\
\hline mean & .089 & .471 & $\overline{.925}$ & -.001 & .0649 & .0698 \\
\hline median & .022 & .394 & .934 & -.000 & .0644 & .0705 \\
\hline 10\% Quantile & .005 & .181 & .805 & -.009 & .0629 & .0678 \\
\hline 90\% Quantile & .193 & .832 & 1.055 & .008 & .0668 & .0720 \\
\hline mean t stat & 1.587 & 5.018 & $18.709^{c}$ & -.577 & & \\
\hline num sig at .05 & 29 & 98 & 98 & 26 & & \\
\hline num sig at .01 & 19 & 97 & 97 & 16 & & \\
\hline \multicolumn{7}{|c|}{ B. Symmetric Adjustment $\left(\lambda_{i}^{+}=\lambda_{i}^{-}\right)$} \\
\hline mean & & .089 & .908 & .010 & .0649 & .0570 \\
\hline median & & .065 & .916 & .010 & .0644 & .0568 \\
\hline 10\% Quantile & & .041 & .701 & -.006 & .0629 & .0530 \\
\hline 90\% Quantile & & .182 & 1.102 & .027 & .0668 & .0610 \\
\hline mean t-stat & & 4.421 & 5.889 & 0.599 & & \\
\hline median t-stat & & 4.023 & 4.542 & 0.667 & & \\
\hline num sig at .05 & & 99 & 97 & 4 & & \\
\hline num sig at .01 & & 93 & 90 & 0 & & \\
\hline \multicolumn{7}{|c|}{ Tests for Symmetric Adjustment } \\
\hline \multicolumn{4}{|c|}{ t-stat: $\lambda^{+}-\lambda^{-}$} & \multicolumn{3}{|c|}{$\chi^{2}: T\left(\log \left(s s e_{r} / T\right)-\log \left(s e_{u} / T\right)\right)$} \\
\hline \multicolumn{4}{|c|}{ mean: -3.937} & \multicolumn{3}{|c|}{ mean: 29.618} \\
\hline \multicolumn{4}{|c|}{ median: -4.140} & \multicolumn{3}{|c|}{ median: 27.992} \\
\hline \multicolumn{4}{|c|}{ num $\leq-2.35^{d}: 86$} & \multicolumn{3}{|c|}{ num $\geq 6.63^{e}: 89$} \\
\hline
\end{tabular}

${ }^{a}$ Estimation period: $1983(10)-1991(9)$. Average T-bill rate $=.0741$. Sample: 99 banks.

${ }^{b}$ Averages over banks and sample period.

${ }^{c}$ For $H_{0}=1$, mean t-stat $=-1.639$

${ }^{d} \operatorname{prob}(\mathrm{t} \leq-2.35)=.01$

${ }^{e} \operatorname{prob}\left(\chi^{2} \geq 6.63\right)=.01$ 
Table 4: NOW and MMDA Deposit Balances Demand Estimates ${ }^{a}$

\begin{tabular}{lcccc}
$\log \left[D_{i t}\right]=a_{i 1}+a_{i 2}\left(r_{t}-R_{i t}\right)+a_{i 3} \log \left[Y_{i t}\right]+a_{i 4} \log \left[D_{i t-1}\right]+v_{i t}$ \\
\hline \multicolumn{5}{c}{ NOW accounts } \\
\hline mean & -.492 & -1.401 & .524 & .747 \\
median & -.323 & -1.158 & .431 & .764 \\
10\% Quantile & -2.634 & -3.213 & .144 & .526 \\
90\% Quantile & 1.571. & -.090 & 1.193 & .927 \\
mean t-stat & -.513 & -2.042 & 3.226 & 14.604 \\
median t-stat & -1.182 & -2.180 & 3.172 & 12.677 \\
num sig at .05 & 47 & 55 & 83 & 99 \\
num sig at .01 & 38 & 33 & 64 & 98 \\
& \multicolumn{1}{c}{ MMDAs } & & \\
mean & 0.909 & -1.653 & -0.001 & .916 \\
median & .716 & -1.610 & -.005 & .930 \\
10\% Quantile & -.286 & -3.100 & -.179 & .846 \\
90\% Quartile & 2.352 & -.497 & .156 & .969 \\
mean t-stat & 1.372 & -1.803 & -0.154 & 31.545 \\
median t-stat & 1.516 & -1.784 & -0.135 & 30.219 \\
num sig at .05 & 33 & 42 & 20 & 95 \\
num sig at .01 & 10 & 19 & 11 & 95 \\
\hline
\end{tabular}

\footnotetext{
${ }^{a}$ Estimation periods same as for NOW MMDA rate equations, respectively.
} 
Table 5.a: NOW and MMDA Premiums:Fixed Deposits

\begin{tabular}{|c|c|c|c|c|c|c|c|}
\hline & \multicolumn{4}{|c|}{$\mathrm{NOWs}^{a}$} & \multicolumn{3}{|c|}{$\mathrm{MMDAs}^{b}$} \\
\hline & $\frac{P}{P}$ & $\mathrm{VR}$ & VNIC & VRR & $\frac{P}{P}$ & $\mathrm{VR}$ & VNIC \\
\hline & \multicolumn{7}{|c|}{ Asymmetric Adjustment } \\
\hline median & .211 & .464 & .170 & .084 & .122 & .229 & .107 \\
\hline $10 \%$ quantile & .080 & .256 & .156 & .020 & -.007 & .100 & .107 \\
\hline \multirow[t]{2}{*}{$90 \%$ quantile } & .366 & .658 & .192 & .101 & .218 & .332 & .114 \\
\hline & \multicolumn{7}{|c|}{ Symmetric Adjustment } \\
\hline median & .153 & .329 & .156 & .020 & .109 & .206 & .097 \\
\hline $10 \%$ quantile & .072 & .320 & .170 & .078 & .014 & .127 & .097 \\
\hline $90 \%$ quantile & .217 & .372 & .156 & .000 & .195 & .292 & .114 \\
\hline
\end{tabular}

${ }^{a}$ Sample size: 74 banks

${ }^{b}$ Sample size: 95 banks. Reserve requirements are zero for MMDAs.

Table 5.b: Median Premiums: Different Models

\begin{tabular}{lcccc}
\hline & \multicolumn{2}{c}{ NOW Accounts } & \multicolumn{2}{c}{ MMDAs } \\
\hline & asymmetric & symmetric & asymmetric & symmetric \\
\hline fixed deposits & .211 & .153 & .122 & .109 \\
var deposits (a) $^{a}$ & .447 & .308 & .050 & .057 \\
var deposits (b) $^{b}$ & .624 & .392 & .087 & .101 \\
\hline
\end{tabular}

\footnotetext{
${ }^{a}$ Present value of deposit rents calculated over a 360-month horizon.

${ }^{b}$ Same as in variable deposits (a) except that interest rate opportunity cost parameters in the deposit balances equations are set to zero.
} 
Table 6.a: NOW Interest Rate Elasticities: Fixed Deposits Asymmetric Deposit Rate Adjustment

(percentage points, per 100 basis point shock)

\begin{tabular}{l|ccc|ccc}
\hline & \multicolumn{3}{|c}{ market rate increase } & \multicolumn{3}{c}{ market rate decrease } \\
\hline $\begin{array}{l}\text { market rate } \\
\text { change }\end{array}$ & median & quant & $\begin{array}{c}90 \% \\
\text { quant }\end{array}$ & median & quant & $\begin{array}{c}90 \% \\
\text { quant }\end{array}$ \\
\hline 50 bs. pts & -0.82 & -1.30 & -0.28 & -0.70 & -1.22 & -0.28 \\
100 & -0.87 & -1.32 & -0.36 & -0.61 & -1.15 & -0.19 \\
150 & -0.91 & -1.34 & -0.32 & -0.50 & -1.09 & -0.00 \\
200 & -0.93 & -1.36 & -0.32 & -0.48 & -1.15 & 0.02 \\
250 & -0.95 & -1.36 & -0.03 & -0.22 & -0.93 & 0.34 \\
300 & -0.97 & -1.37 & -0.36 & -0.07 & -0.64 & 0.75 \\
\hline
\end{tabular}

Table 6.b: NOW Interest Rate Elasticities: Fixed Deposits Symmetric Deposit Rate Adjustment

(percentage points, per 100 basis point shock)

\begin{tabular}{l|ccc|ccc}
\hline & \multicolumn{3}{|c}{ market rate increase } & \multicolumn{3}{c}{ market rate decrease } \\
\hline $\begin{array}{l}\text { market rate } \\
\text { change }\end{array}$ & median & quant & quant & median & quant & $\begin{array}{c}90 \% \\
\text { quant }\end{array}$ \\
\hline 50 bs. pts. & -0.16 & -0.80 & 0.50 & -0.15 & -0.80 & 0.50 \\
100 & -0.16 & -0.79 & 0.48 & -0.15 & -0.80 & 0.52 \\
150 & -0.17 & -0.79 & 0.47 & -0.15 & -0.79 & 0.53 \\
200 & -0.18 & -0.79 & 0.46 & -0.15 & -0.58 & 0.51 \\
250 & -0.18 & -0.78 & 0.45 & -0.14 & -0.78 & 0.52 \\
300 & -0.18 & -0.78 & 0.44 & -0.14 & -0.79 & 0.54 \\
\hline
\end{tabular}

Table 6.c: NOW Durations ${ }^{a}$

(median bank)

\begin{tabular}{lcccc|cccc}
\hline & \multicolumn{3}{c}{ Fixed Deposits } & \multicolumn{3}{c}{ Variable Deposits } \\
\hline & \multicolumn{3}{c}{ asymmetric adj } & \multicolumn{2}{c}{ symmetric adj } & asymmetric adj & symmetric adj \\
\hline $\begin{array}{l}\text { market rate } \\
\text { change: }\end{array}$ & plus & minus & plus & minus & plus & minus & plus & minus \\
\hline 50 bs.pts & 1.01 & 0.83 & 0.17 & 0.17 & 0.04 & 2.55 & -0.39 & -0.12 \\
100 & 1.09 & 0.70 & 0.17 & 0.15 & 0.06 & -0.04 & -0.39 & -0.41 \\
150 & 1.16 & 0.56 & 0.17 & 0.15 & 0.09 & -0.19 & -0.39 & -0.42 \\
200 & 1.20 & 0.53 & 0.18 & 0.15 & 0.07 & -0.14 & -0.37 & -0.42 \\
250 & 1.24 & 0.53 & 0.18 & 0.14 & 0.09 & -0.41 & -0.37 & -0.43 \\
300 & 1.28 & -0.7 & 0.19 & 0.14 & 0.11 & -0.99 & -0.37 & -0.44 \\
\hline
\end{tabular}

${ }^{a}$ Durations measured in years. For explanation of duration, see text. 
Table 7.a: MMDA Interest Rate Elasticities: Fixed Deposits Asymmetric Deposit Rate Adjustment

(percentage points, per 100 basis point shock)

\begin{tabular}{l|ccc|ccc}
\hline & \multicolumn{3}{|c}{ market rate increase } & \multicolumn{3}{c}{ market rate decrease } \\
\hline $\begin{array}{l}\text { market rate } \\
\text { change }\end{array}$ & median & quant & quant & median & quant & $\begin{array}{c}90 \% \\
\text { quant }\end{array}$ \\
\hline 50 bs. pts. & -0.42 & -0.78 & -0.16 & -0.30 & -0.66 & -0.06 \\
100 & -0.45 & -0.82 & -0.18 & -0.24 & -0.57 & 0.03 \\
150 & -0.48 & -0.87 & -0.21 & -0.16 & -0.48 & 0.18 \\
200 & -0.51 & -0.90 & -0.25 & -0.14 & -0.43 & 0.22 \\
250 & -0.54 & -0.92 & -0.27 & 0.02 & -0.37 & 0.51 \\
300 & -0.56 & -0.94 & -0.28 & 0.16 & 0.32 & 0.72 \\
\hline
\end{tabular}

Table 7.b: MMDA Interest Rate Elasticities: Fixed Deposits Symmetric Deposit Rate Adjustment

(percentage points, per 100 basis point shock)

\begin{tabular}{l|ccc|ccc}
\hline & \multicolumn{3}{|c}{ market rate increase } & \multicolumn{3}{c}{ market rate decrease } \\
\hline $\begin{array}{l}\text { market rate } \\
\text { change }\end{array}$ & median & quant & quant & median & quant & $\begin{array}{c}90 \% \\
\text { quant }\end{array}$ \\
\hline 50 bs. pts. & -0.16 & -0.58 & -0.28 & -0.14 & -0.60 & 0.32 \\
100 & -0.15 & -0.59 & 0.28 & -0.14 & -0.59 & 0.32 \\
150 & -0.15 & -0.59 & 0.28 & -0.13 & -0.59 & 0.33 \\
200 & -0.16 & -0.59 & -0.28 & -0.14 & -0.57 & 0.31 \\
250 & -0.16 & -0.59 & -0.27 & -0.13 & -0.58 & 0.32 \\
300 & -0.16 & -0.59 & 0.26 & -0.12 & -0.59 & 0.34 \\
\hline
\end{tabular}

Table 7.c: MMDA Durations

(median bank)

\begin{tabular}{lcccc|cccc}
\hline & \multicolumn{3}{c}{ Fixed Deposits } & \multicolumn{3}{c}{ Variable Deposits } \\
\hline \multicolumn{3}{c}{ asymmetric adj } & \multicolumn{2}{c}{ symmetric adj } & asymmetric adj & symmetric adj \\
\hline $\begin{array}{l}\text { market rate } \\
\text { change: }^{a}\end{array}$ & plus & minus & plus & minus & plus & minus & plus & minus \\
\hline 50 bs. pts. & 0.46 & 0.32 & 0.17 & 0.14 & 0.41 & 0.34 & 0.19 & 0.19 \\
100 & 0.50 & 0.25 & 0.16 & 0.14 & 0.42 & 0.32 & 0.17 & 0.20 \\
150 & 0.54 & 0.17 & 0.16 & 0.14 & 0.42 & 0.25 & 0.16 & 0.21 \\
200 & 0.58 & 0.14 & 0.16 & 0.14 & 0.40 & 0.21 & 0.15 & 0.19 \\
250 & 0.61 & -0.02 & 0.16 & 0.13 & 0.39 & 0.13 & 0.14 & 0.21 \\
300 & 0.64 & -0.17 & 0.16 & 0.13 & 0.36 & -0.07 & 0.13 & 0.24 \\
\hline
\end{tabular}

a"plus" refers to market rate increase and "minus" to decrease. 